\title{
II. Einmarsch und Etablierung der amerikanischen Militärregierung
}

\section{Das Kriegsende}

Als sich die amerikanischen Truppen im April 1945 der mittelfränkischen Region um Ansbach und Fürth näherten, war der Zweite Weltkrieg längst entschieden und die deutsche Wehrmacht überall auf dem Rückzug. Im Osten hatte die Rote Armee die beiden Flüsse Oder und Neiße und die Ränder der Sudeten erreicht. In Ungarn war die deutsche Gegenoffensive zum Stehen gekommen, die Rote Armee bereitete sich zum Angriff auf Wien vor. Im Westen war es der US-Armee am 7. März gelungen, die alte Ludendorff-Eisenbahnbrücke bei Remagen zu überschreiten und einen rechtsrheinischen Brückenkopf zu bilden. Kurz darauf befand sich die gesamte Rheinlinie von Emmerich bis Koblenz in amerikanischer Hand. Das letzte Kapitel in der Geschichte des Dritten Reiches war damit aufgeschlagen.

Zur gleichen Zeit wurden in Washington letzte entscheidende Weichen für die amerikanische Besatzungsherrschaft in Deutschland gestellt. Am 16. März ernannte das amerikanische Kabinett General Lucius D. Clay zum stellvertretenden Militärgouverneur in Deutschland und am 23. März 1945 bereitete Franklin D. Roosevelt dem monatelangen Ringen um die Besatzungspolitik gegenüber Deutschland ein Ende. Er setzte seine Initialen unter die allgemeinen Grundsätze einer Direktive für den Militärgouverneur in der ,initial post-defeat period“, die als JCS 1067 berühmt wurde ${ }^{1}$. Kurz darauf durchbrachen die Amerikaner die deutschen Linien zwischen Main und Neckar, rückten innerhalb einer Woche von Aschaffenburg bis weit südlich von Würzburg vor und konnten dann mit ihren Operationen in Richtung Nürnberg und Donau beginnen. Bevor die amerikanischen Sherman-Panzer aber vor den Toren Ansbachs und Fürths auftauchten, geriet der Vormarsch der US-Truppen entlang der Linie Steigerwald, Frankenhöhe und Schwäbisch Hall nochmals für einige Tage ins Stocken. In dieser von vielen Tälern durchschnittenen Mittelgebirgslandschaft hatten deutsche Einheiten eine Verteidigungslinie aufgebaut, die von den Amerikanern erst nach erbitterten Kämpfen überwunden werden konnte. Danach war der Weg frei nach

1 Zu Clay und JCS 1067 vgl. u.a. Niethammer, Entnazifizierung, S. $236 \mathrm{ff}$.; John Gimbel, Amerikanische Besatzungspolitik in Deutschland 1945-1949, Frankfurt/Main 1971, S. 16-58; John H. Backer, Die deutschen Jahre des Generals Clay. Der Weg zur Bundesrepublik 1945-1949, München 1983, S. 16f., S.60-69 sowie Wolfgang Krieger, General Lucius D. Clay und die amerikanische Deutschlandpolitik 1945-1949 (unveröffentlichtes Manuskript) und Jean Edward Smith (Hrsg.), The Papers of General Lucius D. Clay, Bloomington 1973, 2 Bde. 
Mittelfranken und Nürnberg, der „Stadt der Reichsparteitage“, die die amerikanischen Truppen fast "magnetisch“ anzuziehen schien ${ }^{2}$.

Nach dem Fall von Würzburg und Bamberg stieß die 7. US-Armee von Generalleutnant Alexander M. Patch mit dem XV. Korps und dem XXI. Korps in den Raum Nürnberg vor. Die auf dem linken Flügel des XXI. Korps von Generalmajor Frank W. Milburn operierende 42. Infanterie-Division wurde unmittelbar vor dem Angriff auf Fürth dem XV. Korps von Generalmajor Wade H. Haislip unterstellt, weil das gesamte Nürnberger Kampfgebiet unter ein Kommando kommen sollte. Am 19. April 1945 nahm die 42. Division („Rainbow Division“) unter Generalmajor Harry J. Collins die Stadt Fürth. Einen Tag vorher waren die Panzer des Combat Command $R$ und des Combat Command A der 12. US-Panzer-Division („Hellcats“) von Generalmajor Roderick R. Allen, die beim XXI. Korps geblieben war, in Ansbach eingerollt. Unmittelbar danach kam das gesamte Operationsgebiet östlich der Linie Würzburg-Ansbach zum Sektor von Generalleutnant George S. Pattons berühmter 3. US-Armee ${ }^{3}$.

Die amerikanische Besetzung "unserer" Region war aber keineswegs kampf- und konfliktlos geschehen. Die letzten Tage vor dem Einmarsch der amerikanischen Streitkräfte blieben vielen als überaus dramatisch in Erinnerung. Anfang April standen die Amerikaner etwa $50 \mathrm{~km}$ vor Ansbach und Fürth. Schon war in den beiden Städten Geschützdonner zu hören. Versprengte Truppenteile und Transporte mit Verletzten fluteten zurück. „Auf Fahrrädern und in Kinderwägen fuhren sie ihre Habseligkeiten, oft in zerrissenen Uniformen und so manche mit blutverkrusteten und verdreckten Verbänden. " ${ }^{4}$ In den Stadt- und Landkreisen Ansbach und Fürth hatte man schon Ende 1944 Vorbereitungen für den Fall einer „Feindannäherung“ getroffen. Franken, „der deutscheste aller Gaue“, sollte dem Feind nicht kampflos in die Hände fallen. „Wir werden kämpfen wie die Löwen mit fanatischer Wut um jeden Fußbreit Boden. Sollte der Feind in Franken eindringen, so werden wir ihn packen und vernichten“, hieß es in einem von Gauleiter Karl Holz, dem Reichsverteidigungskommissar des Gaues Franken, unterzeichneten Aufruf'. Diese markigen Worte bekamen für Fürth und Umgebung eine besonders bedrohliche Note, weil Fürth in die Planungen zur „Rundum“-Verteidigung Nürnbergs einbezogen war. An den Ufern des kleinen Flüßchens Rednitz sollten die Amerikaner zum Stehen gebracht werden.

Die Absichten des Gauleiters riefen einen kleinen Kreis von beherzten Fürther Honoratioren auf den Plan, die das Schlimmste verhindern wollten. Dazu gehörten u.a. Stadtkämmerer Adolf Schwiening, der erste Oberbürgermeister nach Kriegsende, Regierungsdirektor Otto Graf, der spätere Landrat von Fürth ${ }^{6}$, und als treibende Kraft der Leiter der Fürther Lazarette, Dr. Fritz Gastreich. 1895 geboren, in großbürgerli-

2 Albert Kesselring, Soldat bis zum letzten Tag, Bonn 1953, S. 297. Zum Kriegsgeschehen 1944/45 vgl. auch Klaus-Dietmar Henke, Die amerikanische Besetzung Deutschlands, München 1988 und Lothar Gruchmann, Der Zweite Weltkrieg. Kriegführung und Politik, München 1982.

3 Vgl. Seventh United States Army. Report of Operations. France and Germany 1944-1945, Bd. 3, S. $789 \mathrm{ff}$.

4 Reportage über die letzten Kriegstage im Raum Ansbach, in: Fränkische Landeszeitung vom 11. April 1970.

s Fränkische Landeszeitung vom 18. April 1955. Vgl. auch Elke Fröhlich, Die Herausforderung des Einzelnen, in: Martin Broszat/Elke Fröhlich (Hrsg.), Bayern in der NS-Zeit, Bd. VI, München/Wien 1983, S. 232.

$6 \mathrm{Zu}$ den letzten Kriegstagen in Fürth vgl. 8-Uhr-Blatt vom 19. Februar 1952 und vor allem Gottlieb Wunschel, Die Kapitulation von Fürth am 19. April 1945, in: Fürther Heimatblātter, 15 (1965), Nr. 1, S. 7-16; vgl. auch Die letzten Tage Fürths im 2. Weltkrieg, in: Stadtverein. Nachrichtenblatt des Stadtvereins, 21 (1984), Nr. 3. 
chen Verhältnissen und mit den Wertvorstellungen des Kaiserreiches aufgewachsen, Korpsstudent und Stabsarzt in der Wehrmacht, hatte sich Gastreich im Gegensatz zu vielen anderen seiner Herkunft und seines Werdeganges nie für den Nationalsozialismus erwärmen können. Bis zu einem gewissen Grad spielten dabei wohl auch persönliche Gründe mit, denn die Nationalsozialisten hatten 1933 seinen beruflichen Aufstieg zum Leiter des Fürther Stadtkrankenhauses vereitelt. 1938 wurde er von der Liste der Anwärter des NS-Ärztebundes gestrichen, nachdem ihm die Gauleitung Franken bescheinigt hatte: "Ziemliche Interessenlosigkeit gegenüber der Partei." 1944 verfolgte Gastreich den Plan, Fürth zur Lazarettstadt erklären zu lassen, um eine militärische Verteidigung zu verhindern. Er setzte sich dafür ein, zahlreiche Verwundete in der Stadt zusammenzuziehen, und ließ Befehle, die Schwerverwundeten beim Näherrücken feindlicher Truppen abzutransportieren, unbeachtet. Der Plan führte zwar nicht zum Erfolg, die Anwesenheit von über 3000 Verwundeten trug aber mit dazu bei, daß die lebensnotwendigen Versorgungseinrichtungen, entgegen den Absichten von Holz, unversehrt blieben.

Gastreich stand in enger Verbindung mit Josef Gleixner, einem früheren Matrosen, der bereits beim Umsturz 1918/19 politisch aktiv gewesen war. Von der SPD über die USPD gegen Ende der Weimarer Republik zur KPD gewechselt, hatte er sich später ganz aus der Politik zurückgezogen und ein Obstgeschäft aufgemacht. Seiner kommunistischen Gesinnung war er aber treu geblieben ${ }^{8}$. Der Arzt und der Obsthändler, die außer der Sorge um ihre Heimatstadt wenig gemein hatten, trafen sich im Frühjahr 1945 fast täglich'. Vor allem suchten sie den Stadtkommandanten, Major Georg Flierl, sowie den Führer des Volkssturms, Kreisleiter Karl Volkert, und den Oberbürgermeister, SS-Obersturmbandführer Dr. Karl Häupler, in ihrem Sinne zu beeinflussen. Ihre Überredungsversuche blieben nicht ohne Wirkung. Bald gaben auch Flierl und Volkert zu erkennen, daß sie eine Verteidigung Fürths für sinnlos hielten. Sie konnten sich ja tagtäglich selbst davon überzeugen, daß mit den deutschen Truppen nichts mehr zu gewinnen war. Ganze 2500 Mann standen noch zur Verfügung: zwei schlecht bewaffnete Bataillone, in der Mehrzahl Versehrte, eine sogenannte HJ-Kompanie mit jungen Burschen im Alter zwischen 14 und 17 Jahren, und einige Volkssturmeinheiten. Außerdem war ihnen nicht verborgen geblieben, daß es unter den Soldaten gärte. Viele spülten ihren Kummer mit Alkohol hinunter, der eine oder andere machte sich auch schon mal Luft über das sinnlose „Verteidigungstheater“. Die meisten hätten lieber heute als morgen ihre Waffen fortgeworfen.

In den ersten Apriltagen stieß Holz den ursprünglichen Plan, Verteidigungslinien außerhalb der Städte Nürnberg und Fürth zu errichten, um. Jetzt sollte der Feind innerhalb der Stadtmauern gestellt werden. „Um jeden Stein muß gekämpft werden“, so lautete der neue Befehl des Gauleiters ${ }^{10}$. Daraufhin ließ er Alleebäume fällen, Barrikaden und Panzersperren errichten und die Sprengung kriegswichtiger Objekte vorbe-

7 Vgl. dazu eine Gedenkrede zum Tode von Gastreich, in: Privatbesitz Dr. Eugen Gastreich. Vgl. auch Fürther Nachrichten vom 1. April 1980 und Onolden-Zeitung, 63 (1981), Nr. 189, S. 12 ff.

8 Zu Gleixner vgl. Fränkische Sonntagspost vom 16. April 1955 und Fürther Nachrichten vom 17.-19. April 1965.

9 Ebenda und Fränkische Sonntagspost vom 16. April 1955. Schriftliche Mitteilung von Konrad Grünbaum vom 3. Juni 1981.

10 Fürther Nachrichten vom 17.-19. April 1965; Fränkische Sonntagspost vom 16. April 1965; 8-Uhr-Blatt vom 20. Februar 1952 und 19. Februar 1952. 
reiten. Auch das Kopfsteinpflaster der Straßen wurde aufgerissen, um Steine zum Bau von Verschanzungen und als Abdeckung für MG- und Schützennester heranzuschaffen. Jeder, der sich diesen Maßnahmen widersetzte, mußte fürchten, standrechtlich erschossen zu werden.

Ähnlich rauhe Töne bekam die Bevölkerung Ansbachs schon seit längerem zu hören. Dafür sorgte der Ortskommandant, Dr. Ernst Meyer, ein hartgesottener Offizier und blindgläubiger Hitler-Anhänger, der seit 1944 auf dem nahegelegenen Flugplatz Katterbach stationiert und am 27. März 1945 zum Kampfkommandanten von Ansbach ernannt worden war. Der 50jährige Luftwaffen-Oberst, Mitglied der NSDAP seit 1933, hatte es auf seinen „heiligen Eid“ genommen, Ansbach, den strategisch wichtigen Eisenbahnknotenpunkt westlich von Nürnberg, bis „zur letzten Patrone“ zu verteidigen, obwohl der Bahnhof bei den Luftangriffen vom 22./23. Februar 1945 fast total zerstört worden war. Aus Versprengten bildete er neue Einheiten und stellte ihnen Flakgeschütze, sowjetische Beutekanonen, Infanteriegeschütze und Bordwaffen, die er aus nicht mehr einsatzfähigen Flugzeugen des Flugplatzes Katterbach ausbauen ließ, zur Verfügung. Diese Einheiten und einige $8,8 \mathrm{~cm}$ Batterien postierte Meyer dann entlang eines Verteidigungsringes, der in wenigen Kilometern Entfernung um die Stadt Ansbach herumlief.

Meyer, der bis zuletzt an den Endsieg glaubte, schien zu allem entschlossen. In seinen Anweisungen an die Ansbacher Bevölkerung ging er sogar noch über den berüchtigten OKW-Befehl aus dem Führerhauptquartier vom 12. April hinaus, wonach Städte an wichtigen Verkehrsknotenpunkten bis „zum äußersten verteidigt und gehalten“ werden mußten. Jeder, „der eine Waffe tragen kann“, hieß es in der Bekanntmachung des Ansbacher Kampfkommandanten vom 14. April, sei dazu verpflichtet zu kämpfen. „Häuser, die die weiße Fahne zeigen, werden angezündet, die Schuldigen erschossen. Der Werwolf bekämpft den Feind und richtet den Verräter. Feindfreie Orte sind sofort wieder zu besetzen und durch Sperren erneut zu sichern." In den letzten Kriegstagen wurde er zum „aggressiven Amokläufer gegen die Wirklichkeit der Niederlage“. Wer allzu laut am Endsieg zweifelte, riskierte sein Leben ${ }^{11}$.

Die drakonischen Maßnahmen eines Meyer änderten aber an der mangelnden $\mathrm{Be}$ reitschaft des größten Teils der Bevölkerung, den amerikanischen Streitkräften Widerstand entgegenzusetzen, nichts mehr. Der Glaube an den Sieg ist dahin, vertraute selbst Goebbels am 17. März in den Katakomben der Reichskanzlei seinem Tagebuch an, „man hat das dumpfe Empfinden, daß selbst die besten Argumente bei einem

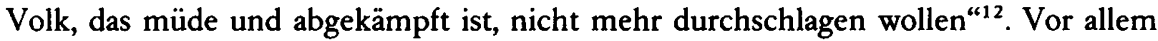
die vollständige Luftherrschaft der amerikanischen Flugzeuge war ein sicheres Vorzeichen der Niederlage. Nach den schweren Bombenangriffen auf Nürnberg, Fürth und Ansbach im Februar und März mehrten sich in den März- und Apriltagen die Tieffliegerangriffe. „Einzelne feindliche Flieger griffen im Tiefflug die Eisenbahnzüge, die Fuhrwerke und Autos auf den Landstraßen und die Bauern auf dem Felde an." ${ }^{\text {"13 }}$ Wegen der häufigen Fliegerangriffe erlitt auch die Kinderlandverschickung, so schrieb der Regierungspräsident von Ober- und Mittelfranken am 15. März 1945, „einen

$11 \mathrm{Zu}$ Ansbach im Frühling 1945 vgl. Fröhlich, Herausforderung, S. 228-254; zit. nach S. 245.

12 Joseph Goebbels, Tagebücher 1945. Die letzten Aufzeichnungen, Hamburg 1977, S. 285.

13 Ortschronik der Stadt Zirndorf, in: Rathaus Zirndorf. 
schweren Schlag“. Die Eltern befürchteten, daß die Lager nicht mehr lange verschont bleiben würden. Manche sagten: „Wir wollen mit unseren Kindern gemeinsam sterben." ${ }^{14}$

An einen wirkungsvollen Gegenschlag, den Goebbels seinen Volksgenossen prophezeite, glaubten nur noch eingefleischte Nationalsozialisten. Sollte er etwa mit den Pimpfen geführt werden, die am 25. März um 8 Uhr morgens auf dem Ansbacher Schloßhof die Verpflichtung der Jugend feierten und von Kreisleiter Seitz mit den Worten entlassen wurden: Der „Tag der Verpflichtung sei ein Tag von höchster Bedeutung, an diesem Tag ergehe der Ruf an sie, Kämpfer zu sein an der Seite des Führers"15? Oder mit den 15-, 16jährigen Buben, die jetzt noch Stellungsbefehle erhielten? Viele Eltern sahen darin nur noch eine Bankrotterklärung des NS-Regimes und wehrten sich trotz schärfster Drohungen heftig gegen die Einberufung ihrer Söhne. Sie schickten ihre Kinder zu Verwandten oder versteckten sie in Scheunen und auf Dachböden. Im „Schicksalskampf des Deutschen Volkes“, den Hitler in seiner letzten Rundfunkrede am 30. Januar 1945 proklamiert hatte, wollten nur noch wenige ihr Leben riskieren. „In fast allen Briefen“, so hatte die Feldpostprüfstelle beim AOK 19 in ihrem Monatsbericht vom 3. April 1945 festgehalten, „wird der Wunsch ausgesprochen, diese Endphase gesund zu überstehen, um nachher mit den Angehörigen wieder vereint zu sein. “16 Der Kampf war aussichtslos geworden. Die Überlegenheit der alliierten Streitkräfte, von der auch die Frontsoldaten an ihre Angehörigen in der Heimat berichteten, war zu offenkundig.

Gegen die Kriegsmüdigkeit konnte auch die immer noch auf Hochtouren laufende deutsche Propaganda nicht mehr viel ausrichten. Unter der Überschrift „Gleiche Brutalität und Gemeinheit“ brachte die Fränkische Zeitung am 28./29. März 1945 einen Bericht einer Frau aus Dillingen-Pachten, der den Ansbachern zeigen sollte, daß „kein Unterschied zwischen Anglo-Amerikanern und Sowjets“ bestehe: „Als die NordAmerikaner den Ort ... besetzten, schossen sie blindlings in jedes Haus ... Dabei wurde in dem Dorf nicht mehr gekämpft ... Alle Lebensmittelvorräte wurden entweder beschlagnahmt oder ungenießbar gemacht. Ich hörte viele amerikanische Offiziere und Soldaten sagen, wenn wir etwas zu essen haben wollten, müßten sich unsere jungen Mädchen und Frauen ihnen als Dirnen zur Verfügung stellen.“ Doch die Schrekkensbilder von den ,verbrecherischen Ausschreitungen der anglo-amerikanischen Soldateska" ${ }^{17}$, die die Bevölkerung zu erhöhter Verteidigungsbereitschaft anspornen sollten, verfehlten ihre Wirkung. „Der Mann auf der Straße in Deutschland erwartet [von den Amerikanern] eine mildere Behandlung; er nimmt an, daß sie wohl ein hartes Regime einsetzen, aber keine Unmenschlichkeiten begehen würden “18, hatte die Neue Zürcher Zeitung schon im Herbst 1944 treffend geschrieben.

Selbst die meisten NS-Funktionäre glaubten nicht mehr an den „Sieg des Deutschen Volkes“. In aller Stille vergrub der Zellenleiter in Petersaurach wenige Tage vor dem Einmarsch der Amerikaner „den Schriftwechsel, nationalsozialistische Bücher

\footnotetext{
14 RegPräs an bay. Staatsregierung, 15. März 1945, in: BayHStA, MA 106696.

15 Fränkische Zeitung vom 27. März 1945.

16 In: Bundesarchiv/Militärarchiv, RH 20-19/245.

17 Vertrauliche Information vom 10. Januar 1945, zit. nach Horst Hano, Die Taktik der Pressepropaganda des Hitlerregimes 1943-1945, München 1963, S. 98.

18 Neue Zürcher Zeitung vom 20. Oktober 1944 (Morgenausgabe).
} 
und sonstige Gegenstände, die mit der Partei im Zusammenhang waren “19. Zahlreiche Parteigenossen lösten ihre Bankkonten auf und versteckten ihr Geld ${ }^{20}$. Viele „Goldfasane“ legten nun ihre Uniformen, mit denen sie jahrelang zu imponieren gesucht hatten, in die Ecke und kleideten sich in Zivil. Die Parteiabzeichen wurden vom Revers genommen, Parteiausweise und Hakenkreuzfahnen verbrannt, braune Hemden und Jacken umgefärbt. Aus den Wohnstuben und Kanzleien verschwanden die Hitlerbilder. Lediglich bei einigen wenigen Parteifunktionären und Beamten hielt sich noch fanatische Hitlergläubigkeit. Sie harrten unverdrossen aus und warteten auf den Einsatz der oft versprochenen Wunderwaffen.

In den letzten Tagen und Wochen vor dem Einmarsch der Amerikaner waren in Ansbach und Fürth die Gasthöfe und Wirtsstuben voll, die Wirte konnten Rekordumsätze an Wein und Bier verbuchen. Die Kinos waren ausverkauft, im März/April kamen in Ansbach „Philharmoniker“ mit Will Quadflieg und „Engel mit dem Saitenspiel“ mit dem damaligen Traumpaar Herta Feiler und Heinz Rühmann zur Aufführung. Fast verzweifelt versuchten sich die Menschen wenigstens durch ein bißchen Privatheit und Vergnügen abzulenken ${ }^{21}$. Doch immer wieder heulten die Sirenen, Stunde um Stunde mußte man in den stickigen Luftschutzkellern zubringen, dicht an dicht mit Nachbarn und Fremden. 3000 Menschen fanden im Großbunker am Fürther Stadttheater Platz. Die Schutzsuchenden bangten und beteten. Im Keller des Pfarrhauses in Heilsbronn saßen über 40 Personen. „Der Ortsgeistliche“, so hieß es in einem zeitgenössischen Bericht, „sprach ... Gebete mit der Bitte um Behütung und Bewahrung. Das Vaterunser wurde von allen Anwesenden, ganz gleich, ob kirchlich oder unkirchlich eingestellt, laut mitgesprochen." 22 Frau Heinold, eine fünfzigjährige Schneiderin aus Leutershausen im Landkreis Ansbach, schrieb damals in ihr Tagebuch: „Dienstag, 17. April 1945. Dienstag mittag um 2 Uhr gingen wir in den Keller. (Hirschenwirtkeller). Die Großmutter nahmen wir auch mit im Liegestuhl. Es war zwar nicht schön, aber es ging. Zwei Tage und Nächte brachten wir im Keller zu. Am Mittwoch in der Nacht kam einer und sagte, wir sollten beruhigt sein, es kämen früh 5.15 die Panzersperren weg. Wir freuten uns alle, doch wenigstens ein Lichtschimmer nach den Aufregungen. Kaum einige Minuten später schrie einer in den Keller hinunter, in 10 Minuten müßte der Keller geräumt sein, denn er würde in die Luft gesprengt. Die Panik kann man sich ja vorstellen, die unter den Menschen ausbrach. Denn jeder hatte soviel Gepäck dabei. Der Bürgermeister beruhigte uns wieder. Es hatte sich nur einer einen dummen Scherz erlaubt.“23

Am 13. April wurde in Fürth der Bahnverkehr eingestellt, die vorhandenen Waggons weggeschafft und die Schalter zugemacht. „Alle Betriebe hatten geschlossen. Nur Metzgereien, Bäckereien und Nahrungsmittelgeschäfte mußten zur Verhütung einer Panik offenhalten. “24 Am 15. April fiel der elektrische Strom aus, man mußte sich mit Kerzen behelfen. Auch die Radios blieben jetzt stumm, die Zeitungen hatten schon

19 Ortschronik von Petersaurach. Gleiches ist in Vach geschehen. Vgl. Bericht über eine Inspektionsreise der Militärregierung im Landkreis Fürth vom 22. Juni 1945, in: LRA Fürth, EAP 070/1.

20 Vgl. Cumulative Report, Det. Fürth, 22,-25. Juni 1945, in: NA, RG 260, 9/96-1/12.

21 Vgl. dazu die Ausgaben der Fränkischen Zeitung vom März 1945.

22 Bericht über die Besetzung Heilsbronns durch amerikanische Truppen am 17. April 1945, in: LKA Nürnberg, Bestand: Dekanat Windsbach, Nr. 313.

23 Privatbesitz von Frau Heinold, Leutershausen.

24 Wunschel, Kapitulation von Fürth, S.9. 
Wochen vorher ihr Erscheinen eingestellt. Informationen über die Kampfhandlungen wurden nun noch spärlicher. Gerüchte gingen um: „Fürth werde nicht verteidigt, war eines von den vielen Gerüchten. Die Verteidigungsgrenze von Nürnberg beginne an der Pegnitz. Dann hieß es wieder, eine Verteidigung vor den Toren Nürnbergs habe keinen Zweck, wenn Fürth unverteidigt in der Angriffszone liege. Deshalb müsse die Verteidigung bereits westlich von Fürth beginnen." ${ }^{\text {25 }}$

In den beiden Städten Ansbach und Fürth wurden schließlich auch die Nahrungsmitteldepots geöffnet. Die vollen Lager sollten dem Feind nicht in die Hände fallen: „Es war ein gespenstischer Anblick“, erzählte später ein Ansbacher. „Die Leute waren wie verrückt. Keiner ließ sich mehr halten, obwohl schon vereinzeltes Artilleriefeuer in der Stadt lag. In der Endresstraße angekommen, zwängten sich die Leute mit ihren Karren und Wagen durch eine knapp zwei Meter breite Öffnung der dort errichteten Panzersperre aus mächtigen Baumstämmen. Es war ein Mordsdurcheinander ... An die 100 Frauen, Kinder, Jugendliche und Opas tummelten sich aufgeregt herum wie auf einem Jahrmarkt ... Bis zur Decke war die gute Hälfte der Halle mit Kisten voll gestapelt. Einige junge Burschen thronten auf dem Kistenberg wie Barockengel und knallten die Ware herunter. Meist zerbrachen die Kisten klatschend am Boden, so daß nicht wenige Dosen eingedrückt herunterpurzelten. Gierig stürzte sich dann jedesmal die Masse der unten stehenden Frauen und Männer auf den Segen der da von oben kam. “26

Der Geschützdonner kam täglich näher. Jeder wußte, nur noch wenige Tage und der Krieg ist zu Ende. Aber es war noch immer ungewiß, auf welche Weise der Krieg zu Ende gehen wird. In allen größeren Ortschaften des westlichen Mittelfrankens hielten sich kleinere Wehrmachts- und SS-Einheiten auf, die am 29. März den Befehl des Reichsführers SS erhalten hatten, in dem es hieß: „Im jetzigen Zeitpunkt des Krieges kommt es einzig und allein auf den sturen und unnachgiebigen Willen zum Durchhalten an. Gegen das Heraushängen weißer Tücher, das Öffnen bereits geschlossener Panzersperren ... ist mit härtesten Maßnahmen durchzugreifen. Aus einem Haus, aus dem eine weiße Fahne erscheint, sind alle männlichen Personen zu erschießen. Es darf bei diesen Maßnahmen keinen Augenblick gezögert werden. “27 Am 2. April hatte ein Befehl des Führers nochmals eingeschärft, jede Stadt bis zum Letzten zu verteidigen. Das Verhalten der deutschen Truppen war ebensowenig vorherzusehen wie das der Amerikaner. Würden diese, nun, da das Kriegsende so nahe war, die ganze Wucht ihrer Kriegsmaschinerie einsetzen, wenn sie unter Feuer gerieten? Die Dinge standen auf der Kippe, der leiseste Stoß konnte die Richtung entscheiden. In dieser ungewissen Situation hing das Schicksal der Städte und Dörfer auch wesentlich davon ab, ob couragierte Bürger bereit waren, den Lauf der Dinge zu beeinflussen ${ }^{28}$.

Fürth hatte Glück, das Kriegsende verlief letztlich undramatisch. Am Mittwoch, den 18. April 1945 waren das 222. und 242. Regiment der 42. amerikanischen Infanterie-Division bis an den Rand der Stadt vorgedrungen, die als Teil Nürnbergs angese-

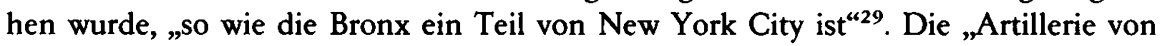

23 Ebenda, S. 10.

26 Fränkische Landeszeitung vom 18. April 1970.

27 In: Bundesarchiv/Militärarchiv, RH 20-19/196.

28 Vgl. dazu Oberkirchenrat Julius Schieder an den Evangelisch-Lutherischen Landeskirchenrat Ansbach, in: LKA Nürnberg, Bestand: Kreisdekan Nürnberg, Nr. 14-502.

29 Geschichte der 42nd „Rainbow“ Infantry Division, S. 84, 0. O., o.J., in: IfZ-Archiv. 
Fürth“, ein einziges Pakgeschütz, schoß nicht mehr; die Mannschaft war von der Bevölkerung zum Abzug überredet worden ${ }^{30}$. Stadtkommandant Flierl - innerlich nicht mehr ganz bei der Sache - wollte die Stellungen noch bis zum Abend halten, um seinen Truppen im Schutz der Dunkelheit den Rückzug zu erleichtern. Immer wieder griff er zum Telefon und versuchte, den Kampfkommandanten von Nürnberg, Oberst Wolf, zu erreichen, um von ihm freie Hand für den Rückzug zu erhalten. Aber es kam und kam keine Verbindung zustande - kein Wunder, denn Gleixner und seine Gruppe hatten die gesamten Verbindungen nach Nürnberg unterbrochen, damit keine Befehle von Holz mehr durchkamen ${ }^{31}$. Gegen $4 \mathrm{Uhr}$ morgens entschloß sich der Major, auf eigene Faust zu handeln. Seine beiden Bataillone marschierten in Richtung Süden ab. Bei Schweinau, einem kleinen Vorort von Nürnberg, trafen sie auf überlegene amerikanische Verbände und gingen in Gefangenschaft ${ }^{32}$.

Die Amerikaner waren in der Zwischenzeit noch näher an den Stadtkern von Fürth herangerückt. Das 2. Bataillon des 222. Regiments hatte im Westen bereits die Regnitz überquert, das 3. Bataillon tastete sich von Norden her über die eingefallenen Stahlträger einer gesprengten Brücke Richtung Stadtmitte vor. Im Morgengrauen ging das 3. Bataillon des 242. Regiments bei Dambach über die Regnitz, das 1. Bataillon folgte kurz danach. Einige Fürther Bürger, die davon wußten, eilten daraufhin ins Rathaus und drängten Oberbürgermeister Karl Häupler, die nötigen Schritte zur kampflosen Übergabe der Stadt zu tun. Die weiße Fahne brachten sie gleich mit. Doch Häupler lehnte ab - nicht weil er es mit seiner Ehre als Soldat nicht hätte vereinen können. Er hatte einfach Angst um seine Familie, die ins Allgäu evakuiert worden war und womöglich Repressalien zu gewärtigen hatte. Um $10 \mathrm{Uhr}$ vormittags erhielt der frühere Stadtrat Hans Teichmann von der SPD, der am Westrand der Stadt wohnte, Besuch von einem amerikanischen Leutnant, der ihn bat, sofort zu dem befehlshabenden amerikanischen Offizier zu kommen. Teichmann tat wie ihm geheißen und wurde aufgefordert, bei der Räumung der westlichen Stadtbezirke mitzuhelfen, die unvermeidlich zur Kampfzone erklärt würden, wenn Häupler nicht bald zur Übergabe der Stadt bereit sei. „Nach dreiviertel Stunden war der Befehl vollzogen und Herr Teichmann erhielt die Weisung, die etwa 2500 Männer, Frauen und Kinder auf Umwegen in die Waggonfabrik an der Würzburgerstraße zu verbringen." ${ }^{\text {“33 }}$

Währenddessen herrschte im Rathaus Hektik. Die ganze Nacht über hatten sich Gastreich und Gleixner beim Oberbürgermeister ${ }^{34}$ aufgehalten und ihn beschworen, endlich zu handeln. Viel Zeit blieb ihm freilich nicht mehr, denn jetzt drängten die Amerikaner ultimativ auf die Übergabe der Stadt. Ein 70jähriger Rentner, der zusammen mit einigen hundert Neugierigen an der schon in amerikanischer Hand befindlichen Maxbrücke stand, schilderte die weiteren Ereignisse so: „Plötzlich kam ein amerikanischer Soldat auf mich zu und frug mich auf deutsch, ob ich wisse, wo der Oberbürgermeister von Fürth wohne. Als ich das bejahte, forderte er mich auf, mit ihm zum amerikanischen Major zu gehen; es passiere mir nichts. Das tat ich. Beim Major angekommen, gab dieser mir einen Zettel und sagte, ich möge diesen Zettel dem

30 Fürther Nachrichten vom 17.-19. April 1965.

31 Vgl. Fränkische Sonntagspost vom 16. April 1955.

32 Vgl. Wunschel, Kapitulation von Fürth, S.8f. und Fürther Nachrichten vom 17.-19. April 1965.

33 Wunschel, Kapitulation von Fürth, S. 11.

34 Ebenda, S. 10 und Fränkische Sonntagspost vom 16. April 1955. 
Oberbürgermeister überbringen, lesen lassen und ihm den Zettel wieder bringen ... Im Rathaus angekommen, frug ich nach dem Sitzungssaal. Man wies mich dorthin und ich trat ein. Den Oberbürgermeister kannte ich persönlich nicht. Ich ging deshalb auf den mir bekannten Stadtkämmerer Schwiening zu, gab ihm den Zettel und sagte, diesen Zettel soll ich im Auftrag eines amerikanischen Majors dem Oberbürgermeister geben, lesen lassen und dann den Zettel dem amerikanischen Major wieder zurückbringen. Stadtkämmerer Schwiening las den Zettel und wandte sich sofort an einen anderen Herrn und sagte: ,Herr Oberbürgermeister, lesen Sie bitte und gehen Sie doch gleich mit dem Überbringer dieses Zettels zu dem amerikanischen Major'“"35

In Begleitung des Rentners und eines Sanitäters traf Häupler wenig später im amerikanischen Quartier ein. Er stellte sich als Oberbürgermeister vor, man bot ihm einen Stuhl an, den er dankend ablehnte. „Meine Herren“, sagte er, als der amerikanische Offizier von ihm die Übergabe der Stadt verlangte, ,ich stehe hier als deutscher Mann und als Oberbürgermeister. Sie wissen, was mir bevorsteht, wenn ich den Befehl zur Hissung der weißen Fahne gebe. Was aus mir und meiner Familie wird, brauche ich nicht weiter zu sagen, nachdem ich nichtwaffentragender SS-Mann bin.“ Daraufhin klopfte ihm der amerikanische Offizier, der offenbar Verständnis für diese prekäre Lage hatte, fast freundschaftlich auf die Schulter und sicherte ihm Schutz zu. Hierauf zog er seine Uhr und sagte: ,Jetzt ist es 10 Uhr 20 Minuten. In einer Stunde erwarte ich eine bestimmte Antwort. Lautet diese ablehnend, werde ich die Beschießung von Fürth befehlen und außerdem noch Flieger anfordern, die schon nachmittags eintreffen und dann Fürth dem Erdboden gleich machen werden. ${ }^{\text {"36 }}$ Der amerikanische Offizier, ein vernünftiger Mann, der unnötiges Blutvergießen vermeiden wollte, fand sich sogar noch zu einem Zugeständnis bereit, als Häupler die gesetzte Frist als zu kurz bezeichnete. Der Oberbürgermeister und seine Begleiter begaben sich dann in das Rathaus zurück, wo Häupler die Wartenden mit knappen Worten über die bevorstehende Übergabe der Stadt unterrichtete ${ }^{37}$. Der Nürnberger Flaksender meldete um 17.40: „Fürth hat schmachvoll kapituliert; Nürnberg hält sich ... Die Schmach der Stadt Fürth aber wird für alle Zeiten in die Geschichte eingehen.“38 Das kümmerte die Fürther aber wenig. Überall hingen weiße Laken aus den Fenstern, am Rathausturm wehte eine weiße Fahne. Ein Pg aus Zirndorf hatte die Tücher dazu „gespendet“. Von Gleixner und seinen Leuten waren sie zusammengenäht worden ${ }^{39}$.

In Ansbach forderte das Schreckensregiment des Dr. Meyer noch in letzter Minute das Leben eines 19jährigen Studenten. Am 18. April befanden sich nur noch wenige Sicherungstruppen in der Stadt. Der Großteil der Soldaten hatte sich nach Süden abgesetzt. Die Spitzen der Partei und der Behörden hatten sich ebenfalls aus dem Staube gemacht. Auch Kreisleiter Seitz, der noch wenige Tage zuvor im Gasthaus „Stern“ wie ein Barockfürst Hof gehalten hatte, stieg in seinen Volkswagen und verschwand auf Nimmerwiedersehen ${ }^{40}$. Daß die Amerikaner schon am Südrand der Stadt standen, wußten viele Ansbacher nicht. Nach den verheerenden Luftangriffen vom 22./23. Fe-

35 Wunschel, Kapitulation von Fürth, S. $13 \mathrm{f}$.

36 Ebenda, S. 15.

37 Ebenda, S. 15 f.

38 Fürther Nachrichten vom 17.-19. April 1955.

39 Ebenda.

40 Vgl. Fränkische Landeszeitung vom 14. März 1970. 
bruar 1945 waren sie vorsichtig geworden. Seit Tagen schon hatten sie nicht mehr gewagt, die Luftschutzkeller zu verlassen. Anders der 19jährige Robert Limpert, ein religiöser, ganz und gar zivilistischer Student, der schon „seit langem ... gegen den martialischen Ungeist des Nazismus und des Krieges“ aufbegehrt hatte ${ }^{41}$. Im Frühjahr 1945 verteilte er heimlich Flugblätter, in denen er zur Übergabe der Stadt aufrief:

\section{„Ansbacher!}

Verteidigung der Stadt bedeutet ihre völlige Vernichtung. Unsere Stadt ist einer der wenigen Orte des Reiches, die noch verhältnismäßig unzerstört sind. Wir wollen sie uns erhalten! Widerstand kann die Amerikaner nicht aufhalten, nur uns den Untergang bringen. Beseitigt die Panzersperren! Verhindert die Verteidigung!

Retten wir die Stadt und das Leben für uns und für Deutschland! $₫ 42$

Für Limpert war die Nähe der amerikanischen Truppen das Signal, nochmals alles zu tun, um einen sinnlosen Verteidigungsversuch zu verhindern. Mutig begab er sich ins Rathaus. Dort traf er den stellvertretenden Bürgermeister Albert Böhm, Alt-Pg und Träger des goldenen Parteiabzeichens, der sich unverhofft zur kampflosen Übergabe der Stadt überreden ließ. Kurze Zeit vorher hatte Böhm einer Delegation von Ansbacher Frauen, die mit der gleichen Absicht zu ihm gekommen war, die Tür gewiesen. Die Nachricht von der kurzbevorstehenden Übergabe der Stadt verbreitete sich wie ein Lauffeuer. Viele wagten sich jetzt wieder auf die Straße. Auf der Promenade und in der Altstadt bildeten sich Menschentrauben. Einige Ansbacher, die noch vom Willen zum Weiterkämpfen beseelt waren und dies laut sagten, wurden von der Menge fast verprügelt. Zufällig kam die Nachricht auch dem fanatischen Kampfkommandanten zu Ohren, der sofort ins Rathaus stürmte und Böhm solange zusetzte, bis der Alte Kämpfer wieder umschwenkte. Als Limpert davon erfuhr, wurde er noch kühner. Den Plan, Meyer zu erschießen, ließ er auf Zuraten seines Vaters fallen. Dafür durchschnitt er in aller Öffentlichkeit ein Kabel, das die Telefonverbindung zwischen dem Gefechtsstand des Kampfkommandanten und den vor der Stadt postierten Truppen herstellte. „Er riskierte alles, ohne etwas zu bewirken “43, denn der Gefechtsstand war bereits Tage vorher verlegt worden.

Zwei Hitler-Jungen, die Limpert beim Durchschneiden der Drähte beobachtet hatten, meldeten den Vorfall der Polizei, die den Studenten sofort verhaftete. Bei der Durchsuchung seiner Wohnung kamen auch die Flugblätter zutage. Überzeugt, einen Mann vor sich zu haben, der „landesverräterische Anschläge in großer Zahl verbreitet hatte“, drängte Meyer, der sich Limpert sofort vorführen ließ, auf die Bildung eines Standgerichts. Er selbst war Ankläger und Richter, er diktierte auch das Urteil: „Ich verurteile Limpert zum Tode. Das Urteil wird sofort vollstreckt.“ 15 Minuten später

41 Fröhlich, Herausforderung, S. 228.

42 Ebenda, S. 234.

43 Ebenda, S. 246. 
war Limpert tot, aufgehängt an einem am Rathausbogen eingelassenen Haken ${ }^{44}$. Meyer hielt noch eine kurze Ansprache: „Dies ist ein Volksverräter und Staatsverbrecher, der hängen mußte. “45 Dann schärfte er den Schaulustigen ein, die Leiche müsse solange hängen bleiben, bis sie „stinke“. Kurz darauf verließ er die Stadt ${ }^{46}$. Am Nachmittag, die Leiche Limperts war noch immer nicht abgeschnitten worden, marschierten die Amerikaner in Ansbach ein.

Ein noch schrecklicheres Ende nahm der Krieg im etwa zehn Kilometer westlich von Ansbach gelegenen Leutershausen, das ebenfalls unter dem Regiment des Oberst Meyer stand, der das 1000 Jahre alte Städtchen mit allen Mittel zum Widerstandsnest ausbauen wollte. Hier wurde auf drastische Weise deutlich, welche verheerenden Konsequenzen der sinnlose Widerstand einiger SS-Einheiten haben konnte. In den entscheidenden Stunden vor dem Einmarsch der Amerikaner schien alles auf ein glimpfliches Ende hinzudeuten. Am 18. April, kurz nach Mitternacht, hatte der ranghöchste Wehrmachtsoffizier dem Druck der Leutershausener Bürger nachgegeben, seine Kampfgruppe abrücken lassen und den Volkssturm aufgelöst ${ }^{47}$. Noch in der Nacht räumten Leutershausener Frauen die Panzersperren beiseite - entgegen dem Rat des verbohrten Führers der Volkssturmkompanie, der meinte: „Etwas Dümmeres hättet Ihr nicht machen können, Ihr bringt Schmach und Schande über Leutershausen. “48 Am darauffolgenden Morgen wartete alles bereits gespannt auf den Einmarsch der Amerikaner, als in der oberen Vorstadt neue deutsche Truppen auftauchten. Der Führer dieser kleinen Einheit, ein Oberscharführer der Waffen-SS, bestand darauf, daß alle in der Nacht getroffenen Maßnahmen sofort rückgängig gemacht würden. „Lassen Sie sich nicht einfallen, uns in den Rücken zu fallen oder die weiße Fahne zu zeigen, sonst eröffnen wir das Feuer auf den Ort“, mit diesen Worten führte er dem Bürgermeister den Ernst der Lage vor Augen ${ }^{49}$. Eilends wurden die Panzersperren geschlossen und die Brücke über die Altmühl wieder sprengbereit gemacht.

Im Laufe des Vormittags rückten amerikanische Panzerspähwagen an Leutershausen heran. Als die Waffen-SS das Feuer eröffnete, zogen sich die Amerikaner, die kein Risiko eingehen wollten, sofort zurück und forderten Unterstützung aus der Luft an eine Taktik, die überall zur Anwendung kam, wenn die Bodentruppen auf ernsthaften Widerstand trafen. Im Tagebuch von Frau Heinold lesen wir über die weiteren Ereignisse in Leutershausen: „So zwischen 6 und 7 Uhr abends ging das Schauspiel los. Es kamen die Bomber, vielleicht so 8 oder 10. Auf einmal krachte es. Unser Keller schwankte tüchtig. Alles zitterte und bebte. Wagners und wir beteten immerzu. In einer Viertelstunde brannte unser schönes Leutershausen zur Hälfte lichterloh. Es war einfach furchtbar schlimm. Nun gibt es soviele, die kein Obdach mehr haben. Unsere untere Vorstadt blieb Gott sei Dank verschont, bis auf zerbrochene Fensterscheiben und Dachschäden. Sprengbomben fielen im Krankenhaushof und auf der Insel. Nach dem Angriff kamen die Leute haufenweise in den Keller geflüchtet und die Luft wurde ziemlich dick“so. Wie durch ein Wunder kamen nur zwei Menschen ums Le-

\footnotetext{
44 Ebenda, S. 252.

4s Fränkische Landeszeitung vom 7. April 1970.

46 Fröhlich, Herausforderung, S. 252.

47 Schilderung der Ereignisse im April 1945 von Bürgermeister Schiller, in: Stadtarchiv Leutershausen.

68 Rüger an Bürgermeister von Leutershausen, 9. Mai 1945, in: Stadtarchiv Leutershausen.

49 Schilderung der Ereignisse im April 1945 von Bürgermeister Schiller, in: Stadtarchiv Leutershausen.

so Privatbesitz von Frau Heinold, Leutershausen.
} 
ben. Mehr als 120 Anwesen, Ställe und Scheunen brannten aus oder waren schwer beschädigt $^{51}$. Nachdem sich die SS-Einheit zurückgezogen hatte, nahm Dekan Blendinger die Dinge in die Hand. Über Mittelramstadt ging er den Amerikanern mit einer weißen Fahne entgegen und bat, das Schießen einzustellen ${ }^{\mathbf{3 2}}$.

In fast allen Städten des Territoriums, das die amerikanischen Streitkräfte 1944/45 besetzten, fanden sich Einzelpersonen und Gruppen, die von demselben Mut beseelt waren wie der Leutershausener Dekan und die Fürther Honoratioren. Überall waren nun - da Hitlers Herrschaft zerfiel - Menschen bereit, drastische Strafen, ja sogar ihr Leben zu riskieren, um Schlimmeres zu verhüten. Die Zeit, da man sich geduckt und den Unmut über das NS-Regime nur hinter vorgehaltener Hand geäußert hatte, ging zu Ende. Auch in den winzigen Bauerndörfern und Kleinstädten der Landkreise Ansbach und Fürth faßten sich Ortshonoratioren, Intellektuelle, einfache Leute, Angehörige der republikanischen Weimarer Parteien, aber auch ernüchterte Funktionäre des NS-Regimes ein Herz und versuchten zu retten, was noch zu retten war. In Oberfürberg, einem kleinen Dorf vor den Toren von Fürth, schlich der Stabsarzt Dr. Eugen Gastreich, der jüngere Bruder des uns aus Fürth bekannten Fritz Gastreich, von Schützenloch zu Schützenloch und redete auf Wehrmachtssoldaten ein, sich zurückzuziehen bzw. sich bei ihm krank zu melden. Schließlich nahm er persönlich Kontakt zu den Amerikanern auf und erreichte die Einstellung des Feuers ${ }^{53}$. In der Gemeinde Roßtal hatte sich ein kleines Komitee aus fünf Handwerksmeistern und dem Dorfarzt, drei von ihnen Parteigenossen, gebildet, das auf dem Kirchturm eine weiße Fahne hißte ${ }^{54}$.

31 Schilderung der Ereignisse im April 1945 von Bürgermeister Schiller, in: Stadtarchiv Leutershausen.

52 Hermann Schreiber, Leutershausen, Leutershausen o.J. (1973), S. 271 f. In den ersten Nachkriegsjahren entbrannte unter der Bevölkerung Leutershausens ein heftiger Streit über der Frage, wer für die schrecklichen Ereignisse des letzten Kriegstages verantwortlich sei. Der Zorn der Betroffenen richtete sich unmittelbar nach Kriegsende vor allem gegen den Hauptlehrer und Führer des Volkssturms Rüger. „Der gewesene Kompanieführer des Volkssturms Leutershausen-Land, Hauptlehrer Rüger, hat bei dem Umbruch in Leutershausen zur Verteidigung des Städtleins und der Umgebung eigens aus Büchelberg SS-Soldaten herbeigeholt, nachdem die Besetzung sich reibungslos vollzogen hätte. Dieser Umstand wurde nachträglich einwandfrei festgestellt. Durch dieses Verhalten trägt Rüger die Hauptschuld an dem furchtbaren Unglück, das geschehen ist. Die Bevölkerung hat nun naturgemäß einen furchtbaren Haß gegen ihn und es ist zu erwarten, wenn behördlicherseits nicht eingegriffen wird, daß etwas gegen ihn unternommen wird“, schrieb der spätere Abgeordnete der CSU im bayerischen Landtag, Georg Mack, am 7. Mai 1945 an Landrat Borkholder in Ansbach. Doch schon fünf Tage später wollte Mack nichts mehr davon wissen. Er ließ den Bürgermeister wissen, daß ex nicht in der Lage sei, seine frühere Behauptung aufrechtzuerhalten. Die Spruchkammer Ansbach-Land, die am 13. Februar 1948 über den mittlerweile an einen anderen Ort versetzten Rüger zu befinden hatte, kam zu folgendem Ergebnis: „Weder besaß der Betroffene eine Befehlsgewalt über die in Rede stehende oder irgend eine andere SS-Abteilung, noch liegt ein Beweis dafür vor, daß er jene SS-Leute zu ihrer ebenso großtuerischen wie verbrecherischen Tat herbeizurufen vermocht hätte oder vermocht hat. Damit scheidet die Frage der Verantwortung des Betroffenen für die Verwüstung Leutershausens aus.“ 1948 wollte aber schon niemand mehr an die Ereignisse des 19. April 1945 erinnert werden. Der Stadtrat lehnte es ab, den Spruchkammerbescheid Rügers öffentlich auszuhängen, „um die ganze Angelegenheit nicht wieder unnötig aufzufrischen“. Jahre später war die Frage nach der Verantwortung für die Bombenangriffe vergessen. Im Heimatbuch der Stadt Leutershausen werden nur die nüchternen Daten genannt. Neue Schuldige waren auch schnell gefunden: die Amerikaner, die - ohne von der SS angegriffen worden zu sein - aus heiterem Himmel die Stadt in Schutt und Asche legten. Zu den Ereignissen im April 1945 vgl. die Akten im Stadtarchiv Leutershausen sowie die Unterlagen im LKA Nürnberg, Bestand: Dekanat Leutershausen, Nr. 449.

53 Fürther Nachrichten vom 29. April 1975 und mündliche Mitteilung von Dr. Eugen Gastreich vom 16. Juni 1981.

34 Schriftliche Mitteilung von Michael Wiesinger vom 1. September 1981. 
Unter den „Rädelsführern“ der Aktionen zur Beendigung des Krieges befanden sich bemerkenswert viele Frauen. In Cadolzburg gingen Frauen schon Anfang April auf die Straße, um die örtlichen Behörden zur kampflosen Übergabe des Marktes zu zwingen. Zu einem solchen „Aufruhr“ kam es auch in Merkendorf, und in Wicklesgreuth, einem kleinen Nest bei Petersaurach, lief eine mutige Witwe den Amerikanern entgegen ${ }^{55}$. Solche oftmals ganz spontanen Aktionen waren mit einem beträchtlichen Risiko verbunden, denn der Arm von SS und Partei reichte auch in den letzten Kriegstagen noch bis in den abgelegensten Winkel der Provinz. In Eyb verhaftete die SS den Bürgermeister und brachte ihn vor ein Standgericht, weil in seiner Gemeinde die Panzersperren eingerissen und verbrannt worden waren ${ }^{56}$. Ein kleiner Weiler bei Michelsberg im Landkreis Fürth wurde von der deutschen Artillerie zusammengeschossen, weil Bauern die weiße Fahne gehißt hatten ${ }^{57}$. Die Mitglieder des Roßtaler Komitees hatten es nur einigen unerschrockenen Familien zu verdanken, daß sie nicht der SS in die Hände fielen, die eine regelrechte Treibjagd auf die "Verräter" veranstaltete.

Am 20. April 1945 schwiegen im westlichen Mittelfranken die Waffen. Die Strapazen der Kriegsjahre waren vorüber. Ein Aufatmen ging durch die Dörfer und Städte, deren Bevölkerung nur eines im Sinn zu haben schien: Krieg und NS-Zeit hinter sich zu lassen und schnell zur Normalität zurückzukehren. Die amerikanischen Militärs, die hitlergläubige und kampfentschlossene Deutsche erwartet hatten, reagierten darauf mit Unverständnis und leichtem Spott: „So begierig waren sie, ihren Eroberern gefällig zu sein, daß sie sofort begannen, die Straßensperren niederzureißen, die sie nur wenige Stunden vorher errichtet hatten, um die Fahrzeuge in die Stadt zu lotsen. Ein Befehl erging, die Waffen abzuliefern, und sie beeilten sich, zu gehorchen. Sie lieferten aber nicht nur Waffen ab, sondern alles, was sie ihres Erachtens mit der Wehrmacht in Verbindung bringen konnte. Uniformen, Gasmasken, Helme, NSDAP-Armbinden wurden auf die großen Haufen vor der Stadthalle geworfen ... Sie schienen kein Interesse an den Kämpfen zu haben, die in Nürnberg noch tobten. Dieselben Leute, die Hitler zugejubelt hatten, waren nun bereit, den Streitkräften zuzujubeln, die ihn beseitigten. Die ,Rainbowmen' hatten es schon früher gesehen, aber hier sahen sie es erneut, wie total die Menschen ihre eigenen Soldaten ignorierten, die als Kriegsgefangene durch die Straßen geführt wurden. Sie sprachen ihnen weder Mut zu, wie man es hätte erwarten können, noch verspotteten sie sie, weil es ihnen nicht gelungen war, die Stadt zu verteidigen. Sie schienen sie einfach nicht zu bemerken. Neugierig bestaunten sie die Amerikaner, aber für ihre eigenen Truppen hatten sie kaum einen Blick übrig. Da und dort winkte eine Frau, aber es gab wenige Tränen als diese Männer in die Gefangenenlager gingen. “58

Von Aachen bis Passau und von Köln bis Regensburg - fast überall erlebten die amerikanischen Streitkräfte einen freundlichen Empfang der deutschen Zivilbevölke-

ss Aufzeichnungen über das Kriegsende, in: Archiv der Gemeinde Petersaurach. Vgl. auch Hildebrand Troll, Aktionen zur Kriegsbeendigung im Frühjahr 1945, in: Martin Broszat/Elke Fröhlich/Anton Großmann (Hrsg.), Bayern in der NS-Zeit, Bd. IV, München/Wien 1981, S.654.

s6 Fränkische Landeszeitung vom 15. Juli 1969.

37 Oberkirchenrat Schieder an Evangelisch-Lutherischen Landeskirchenrat, 11. Mai 1945, in: LKA Nürnberg, Bestand: Kreisdekan Nürnberg, Nr. 14-502.

58 Geschichte der 42nd „Rainbow“ Infantry Division, S. 86 f., o. O., o.J., in: IfZ-Archiv. 
rung. "Germans Welcome Invaders", bemerkte die Londoner Times ${ }^{59}$ schon im September 1944. Goebbels, dem dieses Phänomen natürlich nicht verborgen blieb, entsetzte sich darüber. Über das „feige“ und „unterwürfige“ Verhalten der Frankfurter beim Einmarsch der US-Army schrieb er in sein Tagebuch: „Der Feind bringt darüber Berichte, die einem die Schamröte ins Gesicht treiben. Die Amerikaner seien bei ihrem Einzug mit großen Demonstrationen empfangen worden. Die Parole der Frankfurter laute: ,Laßt uns küssen und gute Freunde sein! "60 Die Anwesenheit der „neuen Herren“ der amerikanischen Besatzungsmacht empfanden viele als „Befreiung“ und als „Erlösung vom Naziterror“. Das galt nach der Einschätzung des Landrats von Fürth sogar für einen Teil der Parteimitglieder ${ }^{61}$. Andere hatten aber auch Angst, niemand wußte genaueres über die amerikanischen Soldaten. War von ihnen wirklich, wie es immer hieß, eine anständige Behandlung zu erwarten?

Die Spannung wich oft schnell großer Erleichterung, als die Amerikaner Lebensmittel zur Verfügung stellten, Verbandszeug lieferten, Verwundete versorgten und in benachbarte Krankenhäuser brachten ${ }^{62}$. Eine Hausfrau aus Fürth erinnerte sich noch viele Jahre später an zwei Szenen: Einige Kinder hatten nach dem Ende der Kampfhandlungen als erste den Bunker verlassen. Sie „kamen mit Bonbon und Schokolade zurück. Die hatten sie von den Soldaten bekommen. Wir atmeten auf und sagten, dann sind die Soldaten nicht böse mit uns.“ Ähnliches passierte ihr kurze Zeit später: „Ein Amerikaner kam in einem Jeep gefahren. Wie er in meine Nähe kam, verlangsamte er sein Tempo, winkte mit der Hand und schrie: Moder, Moder. Es war ein blutjunger Mensch. Ich dachte, das heißt bestimmt Mutter. Lächelte und winkte auch. Nun ließ er seinen Jeep ganz stehen, fuhr mit beiden Armen aus dem Fenster und schrie noch lauter Moder, Moder ..."63 Ähnliches erfuhr der 17jährige HJ-Stammführer Fritz Majer aus Leutershausen. Am Tag nach dem verheerenden Luftangriff war ganz Leutershausen auf den Beinen. Überall wurde gelöscht und aufgeräumt. Majer war so eifrig bei der Sache, daß er es gar nicht bemerkte, als ein amerikanischer Sherman-Panzer dicht hinter ihm hielt. Als er dann den Panzer erblickte, wagte er kaum mehr zu atmen. Die NS-Propaganda hatte bei dem HJ-Führer ihre Wirkung nicht verfehlt. Da war er also, der gefürchtete Feind. Zu allem Unglück trug der Stammführer auch noch das HJ-Abzeichen, das er - fast instinktiv - sofort mit seinen Händen verdeckte. Voller Angst, die Hände auf der Brust, stand der junge Majer und wartete. Die Luke des Panzers ging auf, ein baumlanger Neger kam zum Vorschein und - lachte. „Mit einem Schlag“, so Majer später, „war die ganze Propaganda weg. Ich hab das Lachen als befreiend empfunden." 64

Dieses Gefühl der Erleichterung prägte sich umso nachhaltiger ein, als es nur selten von schrecklichen Erlebnissen wie etwa Vergewaltigungen oder größeren Plünderungen getrübt wurde. „In meinem Hause haben sie wirklich jedes Möbelstück unter-

59 The Times vom 14. September 1944.

60 Goebbels, Tagebücher 1945, S. 421.

61 LR Fürth an MilReg, 2. August 1945, in: StA Nürnberg, LRA Fürth (1962), Nr. 40/1. Vgl. auch Weekly Summary, Det. Fürth, 21. Juli 1945, in: NA, RG 260, 9/96-2/12 und Annual Hist. Rep., Det. Fürth, 20. Juni 1946, in: NA, RG 260, 10/81-1/5.

62 Vgl. Oberkirchenrat Schieder an Evangelisch-Lutherischen Landeskirchenrat, 11. Mai 1945, in: LKA Nürnberg, Bestand: Kreisdekan Nürmberg, Nr. 14-502.

63 Erinnerungen an Kriegszerstörungen in Fürth, in: Fürther Heimatblätter 19 (1969), Nr. 1, S. 15.

64 Mündliche Mitteilung von Fritz Majer vom 27. Juli 1983. 
sucht“, schrieb der Pfarrer der evangelischen Pfarrei St. Michael in Fürth, ,jede Schublade geöffnet und die Sachen der Hausfrau durchstöbert, ja jeden Gegenstand in die Hand genommen und allerlei schöne Sachen, wie Uhren, Zigarettenetui, Taschenmesser, gute Bleistifte usw. mitgenommen. ${ }^{\text {“65 }}$ Deutschen die Uhren abzunehmen, war offenbar so verbreitet, daß schon bald der Witz umging: USA bedeute Uhren stehlen's auch. Doch im großen und ganzen zeigten sich die neuen Herren "recht manierlich“, wie es in einer Reportage der Fränkischen Landeszeitung zum 25. Jahrestag des Einmarsches hieß. Der evangelische Pfarrer von Heilsbronn berichtete über seine erste Begegnung mit amerikanischen Soldaten: „Im Pfarrhaus erschienen drei Mann, darunter ein Offizier. Sie durchsuchten das Haus bis auf den letzten Winkel, nahmen aber nichts als Photo und Offiziersdolch des Bruders des Ortsgeistlichen mit, ließen auch nichts aufbrechen ... In den ersten Tagen der Besetzung wurde die Münsterkirche von einem Offizier ... nach versteckten Soldaten, Waffen und Munition durchsucht. Es geschah in völlig korrekter, höflicher Form." ${ }^{\text {"66 }}$ Diesem Urteil hätte der spätere Oberbürgermeister von Ansbach, Rechtsanwalt Ludwig Schönecker, nur zustimmen können. Er hatte nach den schweren Bombenangriffen auf Ansbach im Februar 1945 im außerhalb der Stadt gelegenen Göttelsdorf Zuflucht gefunden; sein Automobil - einen Adler-Triumph Junior - hatte er, mit etwas Heu bedeckt, in der Scheune untergestellt. Als einige Besatzungssoldaten wenige Tage nach dem Einmarsch das Anwesen inspizierten und den Adler-Triumph fanden, ließen sie sich die Schlüssel geben und brausten davon. Schönecker dachte schon, daß er sein Auto nicht mehr zu Gesicht bekommen würde. Doch nach einer halben Stunde Probefahrt gaben die GI's den Wagen zurück $^{67}$.

Es waren Einzelfälle, wenn amerikanische Soldaten plünderten oder deutsche Frauen und Mädchen bedrohten. Vergewaltigungen seien zwar vorgekommen, teilte der Fürther Oberbürgermeister am 3. Juli 1945 dem Regierungspräsidenten in Ansbach in seinem ersten Monatsbericht nach Kriegsende mit, „doch haben sie keinen größeren Umfang angenommen" ${ }^{\text {"68 }}$. Lediglich in kleineren Orten westlich und nördlich von Fürth kam es zu einigen schlimmen Übergriffen vor allem von farbigen GI's: „Vor etwa acht Tagen wurden in der Gegend von Veitsbronn und Langenzenn Neger stationiert. Seit einiger Zeit werden jede Nacht Frauen mißbraucht und Plätze geplündert. Die Farbigen, oft sechs bis acht Mann, verschaffen sich mit Gewalt Eintritt in die Häuser, bedrohen die Männer mit Waffen und mißbrauchen die Frauen." ${ }^{\text {"69 }}$ Auch in Zirndorf sollen „Neger ... Jagd auf Frauen und Mädchen, die sie selbst aus den Häusern holten ${ }^{\text {"70 }}$, gemacht haben. Im gesamten Okkupationsraum der Amerikaner, der

65 Kriegschronik des Evangelisch-Lutherischen Pfarramts St. Michael Fürth 1939-1947, in: LKA Nürnberg, Bestand: Ev.-Luth. Pfarramt Fürth-St. Michael, Nr. 445.

66 Bericht über die Besetzung Heilsbronns durch amerikanische Truppen am 17. April 1945, in: LKA Nürnberg, Bestand: Dekanat Windsbach, Nr. 313.

67 Mündliche Mitteilung von Dr. Ludwig Schönecker vom 17. August 1983.

68 OB Fürth an RegPräs, 3. Juli 1945, in: Stadtverwaltung Fürth, EAP 4.

69 LR Fürth an MilReg, 30. April 1945, in: NA, RG 260, 9/96-1/12.

70 Ortschronik der Stadt Zirndorf, in: Rathaus Zirndorf. Die amerikanische Militärregierung verurteilte derlei Vorfälle mit aller Strenge und scheute sich nicht, gegen Angehörige der eigenen Streitkräfte, die sich etwas zu Schulden kommen ließen, harte Worte zu gebrauchen: „Gewisse Elemente ... haben durch ihr Verhalten die Vereinigten Staaten und die Armee, deren Uniform sie tragen, in Mißkredit gebracht" (Annual Hist. Rep., Det. Fürth, 20. Juni 1946, in: NA, RG 260, 10/81-1/5). Solche Vorkommnisse würden es sehr erschweren, „die Deutschen von der Uberlegenheit der amerikanischen Nation zu überzeugen“ (Weekly Sum- 
im Frühjahr 1945 etwa die Hälfte des gesamten Reichsgebietes umfaßte, sind aber während des ganzen Jahres 1945 wohl nicht mehr als 1000 Fälle von Vergewaltigungen vorgekommen, die von der US-Armee im übrigen sehr drastisch geahndet wurden; 29 Soldaten wurden wegen Notzucht, 15 weitere wegen Mord in Tateinheit mit Vergewaltigung hingerichtet und mehr als hundert zu langjähriger Zwangsarbeit verurteilt $^{71}$.

Am gefürchtetsten waren in diesen ersten Tagen und Wochen nach dem Einmarsch der amerikanischen Truppen die Fremdarbeiter, die ihre Befreiung feierten und sich in einer ausgelassenen Stimmung befanden. Die Jahre der Entbehrungen und Schikanen waren vorbei, viele DP's ließen nun ihrer lange angestauten Wut freien Lauf. In Ansbach drangen sie gewaltsam in Läden und Geschäfte ein und schleppten davon, was sie tragen konnten. Einige erfuhren von Weinvorräten in der Südstadt. „Sie schlugen Löcher in die großen Fässer und ließen den Wein einfach auslaufen, wenn sie genug hatten. ${ }^{\text {“72 }}$ In Fürth stahlen DP's Autos, Motorräder und Lebensmittel, holten Vieh von der Weide oder aus den Ställen und nahmen Passanten auf der Straße Fahrräder und Wertsachen, namentlich Uhren und Ringe, ab. „Aus manchen Schulhäusern“, so die Fürther Schulverwaltung, „war alles, was nur irgend beweglich war, entfernt, Beleuchtungskörper, Schalter und Steckkontakte, Waschbecken, Wasserhähne, Türen und Fenster, Linoleumbeläge, Öfen, vereinzelt sogar Bretter der Holzböden wurden entfernt." $" 73$

Manchmal kam es auch zu Racheakten gegen besonders verhaßte frühere Vorgesetzte. Vor allem in den kleinen Dörfern und abgelegenen Gehöften, in denen fast nur noch Frauen und alte Männer anzutreffen waren, verbreiteten die marodierenden Fremdarbeiter Angst und Schrecken. Die Gendarmerie im Landkreis Ansbach berichtete: „Vom Lager aus suchten diese Ausländer hauptsächlich bei Nacht die umliegenden Dörfer und Einöden auf und raubten und plünderten in Banden bis zu 25 Mann stark eine große Anzahl Bauernhöfe vollkommen aus. Sämtliche Fleischvorräte und sonstige Lebensmittel, sowie sämtliche Kleidungs- und Wäschestücke wurden gestohlen bzw. geraubt. Vielfach besaßen die Bestohlenen nur noch das, was sie am Leibe trugen. Bei den Plünderungen gingen die Täter in der Weise vor, daß sie die Bewohner unter Bedrohung mit Schußwaffen in einen Raum, vielfach in den Keller, trieben, sie dort bewachten und sodann stundenlang das ganze Haus durchsuchten. Das Diebesgut wurde in bereitgestellten Kraftwagen oder Handwagen fortgeschafft. Wenn sich die Bestohlenen zur Wehr setzten, machten die Täter rücksichtslos von der Schußwaffe Gebrauch. In einem Falle wurde ein Bauer erschossen, in einigen Fällen wurden die Bestohlenen schwer verletzt. Unter den Tätern befanden sich vielfach solche Ausländer, die bei den Bestohlenen oder in der Nachbarschaft vorher bedienstet und daher mit den örtlichen Verhältnissen gut vertraut waren ... In den einzelnen Ortschaften wurden bei Nacht Wachen organisiert, die Lärm machten, wenn Gefahr drohte.“"74

mary, Det. Fürth, 13. Oktober 1945, in: NA, RG 260,9/96-2/12). Das war starker Tobak und brachte der zivilen Militärregierung den Vorwurf ein, „Pro-German“ zu sein (Annual Hist. Rep., Det. Fürth, 20. Juli 1946, in: NA, RG 260, 10/81-1/5).

71 Die Angaben beruhen auf der Studie eines General Board genannten, aus hohen Offizieren zusammengesetzten Expertengremiums mit dem Titel: „Military Justice Administration in the Theater of Operations“ (entstanden Ende 1945), S. 15f.; Dwight D. Eisenhower Library, Abilene, General Board, Reports, Box Nr. 9.

72 Fränkische Zeitung vom 18. April 1953.

73 Mehrjahresbericht (1945-1955) des Schulreferats der Stadt Fürth, in: Stadtverwaltung Fürth, EAP 211.

74 Undatierter Bericht des Gendarmeriekreises Ansbach, in: LRA Ansbach, EAP 01-016. 
Es waren entnervende Tage. Úberall richteten sich jetzt die Hoffnungen auf die Militärregierung, die den „potential trouble makers“ nach einigen Wochen tatsächlich Einhalt zu gebieten vermochte.

Während Ende April 1945 die Bevölkerung Mittelfrankens schon erste Erfahrungen im Umgang mit der Besatzungsmacht sammeln konnte, tobten andernorts noch erbitterte Kämpfe um den Endsieg. Am 16. April hatte die russische Großoffensive an der Oder und in Schlesien begonnen, die Briten standen vor den Toren Hamburgs und Bremens, die Franzosen hatten die obere Donau erreicht, die Amerikaner die Elbe überschritten, wo sie am 25. April bei Torgau mit sowjetischen Truppen zusammentrafen. Im „heiligen Schrein der NSDAP“, in Nürnberg, fand am 20. April die erste Siegesfeier der 3. amerikanischen Division auf dem Adolf-Hitler-Platz statt, der zu Ehren des Kommandeurs, Generalmajor O'Daniel, in „Iron-Mike-Place“ umbenannt worden war $^{75}$. Etwa zur selben Stunde, da in Nürnberg die Divisionskapelle die amerikanische Nationalhymne und „Dogface Soldier“ intonierte, versammelten sich im Reichskanzleibunker in Berlin die Spitzen von Staat und Wehrmacht zur gespenstischen Gratulationscour für den letzten Geburtstag des Führers. „Trotz der verzweifelten Situation fanden sie den Führer immer noch voll Zuversicht; die Russen, glaubte er immer noch, würden vor Berlin ihre blutigste Niederlage erleben. ${ }^{c 76} \mathrm{Wie}$ in den Jahren zuvor hatte es sich Goebbels nicht nehmen lassen, über den Rundfunk zu sprechen und die Deutschen zu beschwören, dem Führer und den Sternen auch weiterhin blindlings zu vertrauen. Doch die Resonanz auf den Geburtstag Hitlers, den das Volk schon 1944 nicht mehr wie in den Jahren zuvor in „dankbarer Liebe und Treue" ${ }^{\text {"77 be- }}$ gangen hatte, war sehr gering. Als in den Wohnhäusern die Hitlerbilder vom Nagel genommen wurden, verschwand anscheinend auch Hitler selbst aus dem Denken der Deutschen. Am 20. April nahm kaum jemand vom Geburtstag des Führers Notiz. Man hatte andere Sorgen: „Hitlers Geburtstag. Wir haben weder Licht, noch Wasser, noch Radio“, hieß es im Tagebuch von Frau Heinold. Selbst der Tod des Führers am 30. April hinterließ nur einen „flüchtigen Eindruck“78. Sein Mythos war gänzlich zerfallen ${ }^{79}$.

\section{Die Militärregierung}

Schon wenige Tage nach dem Einmarsch der Amerikaner wehte das Sternenbanner vom Fürther Rathaus, über dem Eingang hing ein Holzbrett mit der Aufschrift „Military Government“. Die Räume, die die Amerikaner im Rathaus beschlagnahmt hatten, dienten als Amtssitz von Captain John D. Cofer, der als Stadtkommandant und Chef der zivilen amerikanischen Militärregierung nun gewissermaßen Stadtoberhaut von Fürth war. Captain Cofer und sein Team, das Detachment B-229, gehörten zum weitgefächerten Apparat der amerikanischen Militärregierung in Deutschland, an dessen

\footnotetext{
75 Fränkische Sonntagspost vom 16. April 1955.

76 Hugh R. Trevor-Roper, Hitlers letzte Tage, Zürich 1946, S. 107.

77 RegPräs an bay. Staatsregierung, 5. Mai 1942, in: BayHStA, MA 106670

${ }_{78}$ Marlis G. Steinert, Hitlers Krieg und die Deutschen, Düsseldorf/Wien 1970, S. 582.

79 Vgl. dazu Kershaw, Hitler-Mythos.
} 
Spitze ein Militärgouverneur für die gesamte US-Zone stand, dem Länder-, Regierungsbezirks- und, als unterste Ebene der Pyramide, Stadt- und Landkreisdetachments zugeordnet waren, deren Stärke je nach Größe der deutschen Orte zwischen einem Dutzend und einigen Hundert Offizieren und Mannschaftsgraden schwankte.

Viele Militärregierungsoffiziere, die - wie Cofer - jetzt in ihren Bestimmungsorten eintrafen, waren zwischen 1942 und 1944 in den Vereinigten Staaten oder später in Großbritannien auf ihre Aufgaben im besetzten Deutschland vorbereitet worden. Die Rekrutierungsbüros hatten es bei der Auswahl des Personals nicht an Sorgfalt fehlen lassen. Viele dieser Männer, die jetzt die Uniform der US-Army trugen, hatten es im Zivilleben zu etwas gebracht, nicht wenige ansehnliche Karrieren in der freien Wirtschaft oder im öffentlichen Dienst gemacht. Ihr Bildungsniveau war beachtlich hoch. Eine 1956 vorgelegte Studie des Operations Research Office der Johns Hopkins University, die auf den Angaben von 800 Angehörigen der amerikanischen Militärregierung basiert, kommt zu dem Ergebnis, daß 91 Prozent ein Jahr, 77 Prozent sogar vier Jahre oder länger ein College besucht hatten. Zwei Drittel hatte dabei den Grad eines Bachelors, 40 Prozent ein Master's Degree erworben ${ }^{80}$. Kein Wunder also, daß die Offiziere durchweg positiv beurteilt wurden. Albert Gore, ein demokratischer Kongreßabgeordneter aus Tennessee, der für sechs Wochen das Leben der einfachen GI's in der US-Army teilte und dabei auch die Arbeit der Militärregierungsdetachments kennenlernte, schrieb nach seiner Rückkehr in die Vereinigten Staaten: „Unser Militärregierungspersonal ist im großen und ganzen kompetent und qualifiziert." ${ }^{81}$ Professor Walter L. Dorn, der selbst eine zeitlang als Ausbilder tätig war, meinte, daß die „Qualität des Militärregierungsoffiziers in der Civil Affairs Division besonders hoch" gewesen sei $^{82}$. Und der kritische Harold Zink, Mitglied des SHAEF-Planungsstabes und Angehöriger von OMGUS, urteilte später: Das amerikanische Personal sei „ziemlich gut" gewesen. Es habe nur einige Offiziere gegeben, „die zur Klasse der Gauner und Halunken gehörten. Einige waren so unverschämt, daß sie offen ihre Absicht zu erkennen gaben, aus ihren Positionen durch Schwarzmarktgeschäfte, Korruption und sogar Plünderungen so viel wie möglich herauszuschlagen. ${ }^{\text {"83 }}$

Captain Cofer und seine Leute hatten bereits eine bewegte Odyssee auf dem europäischen Kriegsschauplatz hinter sich, als sie am späten Abend des 23. April nach einer zweitägigen Fahrt frierend, übermüdet und hungrig in Fürth eintrafen und das Interims-Detachment, das schon seit drei Tagen in Nürnberg erwartet wurde, ablösten. Das Detachment B-229 ${ }^{84}$ war 1944 in Großbritannien zusammengestellt und in Shrivenham, einem 600-Seelen-Dorf südöstlich von Oxford, und Manchester ausgebildet worden. In Manchester, wo die Zielgebiete der Einheiten festgelegt wurden, erhielten die einzelnen Teams „eine ganze Menge solider und wichtiger Unterweisung“; die Offiziere „studierten von dieser Zeit an ständig die besonderen Bedingungen, die wirt-

8o Vgl. A Survey of the Experience and Opinions of US Military Government Officers in World War II, in: IfZ-Archiv.

81 Der Bericht Gores, der auch dem amerikanischen Kongreß vorgelegt wurde, ist in Auszügen wiedergegeben im Monatsbericht der European Civil Affairs Division (ECAD) vom 7. Mai 1945, in: NA, RG 332, ECAD.

82 Walter L. Dorn, Inspektionsreisen in der US-Zone. Notizen, Denkschriften und Erinnerungen aus dem Nachlaß übersetzt und herausgegeben von Lutz Niethammer, Stuttgart 1973, S. 26.

83 Harold Zink, American Military Government in Germany, New York 1947, S. 23 und 32.

84 History of the Detachment from Formation until Arrival at the Pinpointed Area, in: Annual Hist. Rep., Det. Fürth, 20. Juni 1946, in: NA, RG 260, 10/81-1/5. 
schaftlichen, politischen und Verwaltungsstrukturen“ ihrer Bestimmungsorte ${ }^{85}$. „Trained, drilled, briefed, shaken down and polished ${ }^{\text {“86 }}$, wurden sie im September 1944 nach Frankreich verlegt und etwa 35 Meilen südwestlich von Paris, in Rochefort, einquartiert. Es war damals, wie Dorn sich erinnerte, „ein besonders nasser und kalter Herbst. Es gab nicht genügend Raum im Schloß, um die Division unterzubringen, so daß sie in Zelten auf den Hügeln rings umher in Schmutz und Regen lagerte.“ Die Moral der Männer, so Dorn weiter, war ,außerordentlich niedrig wegen des kalten und regnerischen Wetters, wegen der Ungeduld der Offiziere, und weil die ganze Übersiedlung nach Frankreich ohne jede klug geplante Voraussicht vonstatten gegangen war - eine unmögliche Lage, die Tag um Tag und Woche um Woche andauerte. Diese Leute, die da draußen in Dreck und Schlamm auf den Hängen um Rochefort lagen, waren zu bemitleiden." ${ }^{\text {87 }}$

Im Februar 1945 war das trostlose Lagerleben endlich vorbei. Nun ging es an die Front in der Eifel und manch einer wird sich angesichts der erbitterten Kämpfe nach dem Lagerleben zurückgesehnt haben. Der strapaziöse Einsatz dauerte bis Mitte März, dann wurde das Detachment zum G-5 Stab des III. Corps nach Bad Neuenahr/Ahr abkommandiert. Dort verfehlten es Cofer und seine Leute nur knapp, in die große Geschichte einzugehen. Sie waren nämlich dazu ausersehen, als erste amerikanische Militärregierungseinheit über die Brücke von Remagen zu gehen. Daraus wurde aber nichts, denn das Detachment war für den frühen Einsatz im rechtsrheinischen Gebiet nicht genügend gerüstet. Das Team von Cofer blieb noch bis Anfang April an der Ahr, dann erfüllte es in Fredeburg im Rothaargebirge die routinemäßigen "first duties“. Bürgermeister wurden eingesetzt, Einwohner registriert, Displaced Persons versorgt alles Aufgaben, die auch in Fürth auf Cofer und seine Leute zukamen. Am 21. April, Fürth, der Bestimmungsort der Einheit, war schon zwei Tage zuvor eingenommen worden, löste eine britische Einheit die Cofergruppe in Fredeburg ab, die jetzt den Befehl erhielt, sich beim Hauptquartier der 1. amerikanischen Armee für weitere Aufträge zur Verfügung zu halten. Kaum im Hauptquartier angekommen, erging Marschbefehl zur Fahrt nach Fürth in Bayern.

Das Detachment B-229 bestand im April 1945 aus Captain Cofer, zwei Unteroffizieren und sechs einfachen Soldaten. Von der ursprünglichen, in England und Frankreich ausgebildeten achtköpfigen Mannschaft waren nur Cofer und ein Soldat am Zielort angekommen. John Daly Cofer, 1898 in Gainesville/Texas geboren, gehörte gewiß zum Kreis der Besatzungsoffiziere, die der Kongreßabgeordnete Gore als „kompetent und qualifiziert“ bezeichnet hatte. Der Chef der Fürther Einheit genoß den Ruf eines korrekten, ruhigen Mannes mit ausgeprägtem Gerechtigkeitssinn. Er hatte Jura studiert und seit den zwanziger Jahren, erst in seiner Heimatstadt, dann in Austin, als Rechtsanwalt gearbeitet. Früh an politischen Fragen interessiert, hatte er an den AntiTrust-Prozessen der Regierung Roosevelt mitgewirkt. Seit den dreißiger Jahren gehörte er der Demokratischen Partei an, für die er nach seiner Rückkehr in die Vereinigten Staaten auch als Berater seines texanischen Landsmannes Lyndon B. Johnson tätig wurde.

85 Dorn, Inspektionsreisen, S. $26 \mathrm{f}$.

86 The Manchester Phase of the European Civil Affairs Division, 21 February - 1 September 1944, S.1, in: NA, RG 332, ECAD.

${ }^{87}$ Dorn, Inspektionsreisen, S. 27. 
Cofer, der erst 1942 in die US-Armee eingetreten war, galt als ,ausgesprochen deutschfreundlich ${ }^{\text {“88. }}$. Auf seinem Schreibtisch im Fürther Rathaus landeten alle wichtigen Vorgänge. Außerdem sollte er sich um die Kontakte zur Armee kümmern, zugleich präsidierte er dem „Military Government Summary Court“, der schon Ende April die ersten Urteile fällte. Seinem provisorischen Vertreter, einem Stabsfeldwebel, oblagen Fragen der öffentlichen Sicherheit und der Wiederaufbau des weitgehend zerstörten Transportwesens. Er war auch Anlaufstation für viele Deutsche, die sich in dem Glauben an ihn wandten, schon durch ein kurzes Gespräch mit der „allgewaltigen" Militärregierung ihrer Sorgen ledig werden zu können. Ein Obergefreiter tat Dienst in der Schreibstube. Er hatte alle Hände voll zu tun, die zahlreichen Berichte an die vorgesetzten Militärregierungseinheiten zu verfassen. „Berichte! Berichte! Sie machen mich noch ganz verrückt“, stöhnte er manchmal ${ }^{89}$. Zwei Gefreite hielten die Fahrzeuge der Einheit in Stand. Ein anderer, ebenfalls Obergefreiter, sollte für den Aufbau der deutschen Polizei sorgen; ihm sagte man schon bald nach, für den Geheimdienst zu arbeiten. Wieder ein anderer, ein Arzt, widmete sich dem Gesundheitswesen - ein Bereich, dem die Amerikaner aus Furcht vor Seuchen besondere Aufmerksamkeit schenkten. Der Gefreite Rykowski hatte mit der Betreuung von DP's und Flüchtlingen eine gewaltige Aufgabe übernommen. „Ricky“ ${ }^{\text {“9 }}$ beherrschte mehrere slawische Sprachen und agierte mit so großem Geschick, daß er später ebenso wie Cofer die „Bronze Star Medal“ erhielt. „Mädchen für alles“ war schließlich ein Obergefreiter, dem neben seinem zeitraubenden Job als Übersetzer auch die Bereiche Verwaltungsaufbau, Ernährung und Handel und Industrie unterstanden.

Die Stärke der Fürther Einheit änderte sich bis zum Ende der Besatzungszeit häufig. Im Mai 1945 stießen vier neue Offiziere zum Detachment: Captain Carl Barker, ein etwa 35jähriger, bulliger und humorloser Berufssoldat mit starken Ressentiments gegenüber den Deutschen, wie der Fürther Sozialdemokrat Otto Gellinger, der lange mit ihm zusammenarbeitete, später erzählte. „Bezeichnend für seinen Charakter und seine Einstellung waren die Spiele, die er trieb“, so Gellinger, „indem er Zigaretten, Schokolade u.a. auf den Tisch legte, mich sitzen ließ und aus dem Zimmer ging. Nach seinem Kommen prüfte er, ob etwas fehle."91 Barker nahm sich nun des Aufbaus der deutschen Polizei an und befaßte sich später mit Entnazifizierungsfragen. Mit ihm kamen ein Trade and Industry Officer, der sich um den bisher arg vernachlässigten Bereich Handel und Industrie kümmern sollte, und Gilbert N. Harrison, ein Rechtsanwalt aus Brownwood in Texas, der als Legal Officer die deutschen Justizbehörden wieder in Gang setzen und als Ankläger vor dem Militärgericht fungieren sollte. Seit Mai hatte das Detachment schließlich auch einen Deputy Military Government Officer zur Entlastung des vielbeschäftigten Cofer.

Im Juni kam noch ein Property Control Officer hinzu, eine zwielichtige Figur, die "arisiertes" und sonstwie schutzbedürftiges Eigentum sicherstellen und Treuhänder einsetzen sollte. „Mit ihm hatte man nun aber den Bock zum Gärtner gemacht. Es

$88 \mathrm{Zu}$ Cofer vgl. Who's Who in America, Vol. 30, 1958/59 und schriftliche Mitteilung von Otto Gellinger vom 6. November 1981.

89 Annual Hist. Rep., Det. Fürth, 20. Juni 1946, in: NA, RG 260, 10/81-1/5.

90 Det. Fürth an Commanding Officer, 3rd Military Government Regiment, 29. September 1945, in: NA, RG 260, 9/95-1/37.

91 Schriftliche Mitteilungen von Otto Gellinger vom 6. November 1981 und 10. Februar 1983. 
scheint“, so urteilte ein deutscher Angestellter, „daß er weit mehr daran interessiert war, aus seiner Position für sich selber das Beste herauszuholen. Er wurde bald vor ein Kriegsgericht gestellt und nach USA zurückgeschafft."92 An seine Stelle trat im Herbst 1945 Charles R. Mont, ein bald in der ganzen Stadt beliebter, überaus fleißiger Feldwebel. Der hilfsbereite Quäker wurde von den Fürthern nur noch „Mister Mont“ genannt. Man bestürmte ihn mit Fragen, der Eingang zu seinem Dienstzimmer war fast ständig belagert ${ }^{93}$. Im September 1945 erreichte das Detachment B-229 mit einem Dutzend Offiziere, einem Feldwebel und elf einfachen Dienstgraden seine größte Stärke. Später gehörten immer etwa drei Offiziere, ein Feldwebel und fünf Soldaten zur Fürther Einheit. Im ersten Jahr der amerikanischen Besatzung waren insgesamt 17 Offiziere und 23 „Gemeine“ in Fürth tätig. Nur sechs der 17 Offiziere und vier der 23 einfachen Dienstgrade hatten eine spezielle Ausbildung genossen, die übrigen sich kurzerhand von der Armee abwerben lassen. Ernsthafte Beeinträchtigungen des Dienstbetriebes seien durch die mangelhafte Ausbildung vieler Offiziere nicht entstanden, so verlautete aus Militärregierungskreisen, denn immer seien einige Experten vorhanden gewesen, die die "Laien“ aus der Armee einarbeiten konnten ${ }^{94}$.

Für Ansbach als „Hauptstadt“ von Mittel- und Oberfranken und Sitz der Stadt- und Landkreisverwaltung waren zwei amerikanische Detachments vorgesehen: das Detachment F2A3 für den Regierungsbezirk und das Detachment G-228 für den Stadtund Landkreis. Während aber die für den Regierungsbezirk zuständige Einheit schon am 19. April 1945 in Ansbach ankam, ließen die G-228-Leute auf sich warten. Im Mai traf eine Vorhut ein, und erst im Juli war das Detachment komplett. Um die Belange der Stadt und des Landkreises kümmerten sich inzwischen eine Einheit, die eigentlich im benachbarten Gunzenhausen eingesetzt war ${ }^{95}$, und das Regierungsbezirksdetachment, das aber anfangs vollauf mit internen Schwierigkeiten beschäftigt war und so die Belange Ansbachs nur stiefmütterlich behandeln konnte. Sein Chef, Oberst Edward Haight, deutschfreundlich, ein Flugzeug- und Hundeliebhaber, der sich gern in einem schwarzen „Adolf-Hitler-Mercedes“ chauffieren ließ ${ }^{96}$, hatte alle Hände voll zu tun, um sich als Leiter der Militärregierungseinheiten in Ober- und Mittelfranken Anerkennung zu verschaffen. Allzu großen Erfolg konnte er dabei in den ersten Wochen der Besatzung nicht verbuchen. Am 6. Mai stand die Ansbacher Einheit erst mit 10 von ihr insgesamt untergeordneten 33 Kreis-Detachments in Verbindung. Auch später ging in Haights Hauptquartier noch vieles drunter und drüber. Mal erhielten die Außenstellen keine Anweisung, mal gab es mehrere, sich zum Teil widersprechende Direktiven. Erst im Spätsommer 1945 faßte die Einheit langsam Tritt ${ }^{97}$.

92 Robert Herbst, Die Wiederaufrichtung der Justiz in Fürth durch die Amerikaner, April-August 1945, in: Fürther Heimatblätter 20 (1970), Nr. 1, S.2. Vgl. auch Robert Herbst, Episoden. Aus dem Leben eines Alleingängers 1904-1980, Zug 1981, S.64-76.

93 Ebenda.

94 Vgl. Annual Hist. Rep., Det. Fürth, 20. Juni 1946, in: NA, RG 260, 10/81-1/5.

95 G-5, 3. US-Army, an Det. für Ober- und Mittelfranken, 20. Juni 1945, in: NA, RG 260, 9/114-3/19.

96 Mündliche Mitteilung von Robert Joos vom 22. November 1983.

97 Vgl. Det. für Ober- und Mittelfranken an alle Det., 3. Juli 1945, in: NA, RG 260, 9/114-3/19. Vgl. auch 3. US-Army an Commanding Officer, Det. für Ober- und Mittelfranken, 8. Mai 1945: Organisation of Regierungsbezirk; Det. für Ober- und Mittelfranken an alle Det., 7. Mai 1945: Organisation of Regierungsbezirk sowie Det. für Ober- und Mittelfranken an 3. US-Army, 6. Mai 1945: Regierungsbezirk Ober- und Mittelfranken Contacts, in: NA, RG 260, 9/114-3/19. 
Angesichts dieser verworrenen Situation blieb gleichsam vor der Haustür in Ansbach vieles liegen. „Obwohl das Kriegsende schon einige Zeit zurücklag, war in bezug auf Entnazifizierung und die Errichtung einer zivilen Verwaltung für den Stadt- und Landkreis Ansbach noch nicht viel geschehen. ${ }^{“ 98}$ Das änderte sich aber schnell, als das „pin-pointed“-Detachment am 9. Juli 1945 in der Promenade Nr. 4 gegenüber der Ansbacher Residenz sein Hauptquartier aufschlug. Das Detachment bestand zunächst aus 21 Mann, wuchs aber bis September 1945 auf 31 Mitarbeiter an. An der Spitze stand Col. William R. Whitaker, ein 50jähriger, überaus penibler Jurist aus Chicago auch er einer von den exzellenten Kräften in der Militärregierung. „Er war ein fesselnder Mann, so daß Amerikaner und Deutsche gleichermaßen bereit waren, ihm zu folgen“, so charakterisierte ihn einer seiner Mitarbeiter" ${ }^{99}$. Mehr noch als Cofer hatte Whitaker starke Zweifel, ob das Besatzungsregime das „best example of democracy“ sein könne. Er legte größten Wert darauf, „durch das eigene Beispiel - besonders auf der Ebene eines Stadt- und Landkreises - zu zeigen, daß die Militärregierung eine Regierung war, die sich vom Gesetz leiten ließ - von einem Gesetz, dem das Militärpersonal und die DP's ebenso unterworfen waren wie die Besiegten “100. Zu seinen Mitarbeitern zählten kaum Berufssoldaten, sondern Rechtsanwälte, Bauingenieure, ein Polizist, ein Journalist und ein Techniker namens Wilfred T. Eichhorn, der wegen seines Namens und einer gewissen Ähnlichkeit mit General Eisenhower „Ike“ gerufen wurde. Nur wenige sprachen deutsch. Das Detachment war an drei verschiedenen Stellen untergebracht. Die einfachen Dienstgrade teilten sich die Räume der Villa Lutz. Die Offiziere wohnten separat, und Whitaker, auf Distanz zu seinen Untergebenen bedacht, hatte die Villa des Ansbacher Forstamtmanns Lingmann für sich beschlagnahmen lassen.

Von den vielen amerikanischen Offizieren, die sich namentlich in der zweiten Hälfte der Besatzungszeit schnell abwechselten, ist den Ansbachern neben Whitaker vor allem der damals 30jährige Frank Dominic Horvay ${ }^{101}$ in Erinnerung geblieben. Der gebürtige Ungar, der in den dreißiger Jahren wegen seines jüdischen Glaubens in die Vereinigten Staaten emigriert war und erst seit 1942 die amerikanische Staatsbürgerschaft besaß, hatte sich seit seiner Jugend viel mit deutscher Geschichte und Literatur beschäftigt und sprach besser deutsch als englisch. 1943 hatte er sich freiwillig zur US-Army gemeldet und war dann sechs Monate lang an der University of California in Berkeley auf einen Einsatz auf dem Balkan und in Zentraleuropa vorbereitet worden, ehe er 1945 zur G-5 Abteilung der 13. Armored Division abkommandiert wurde. Als einer der ersten des Detachments G-228 kam er am 9. Mai in Ansbach an. Die Einheit, so erinnerte er sich später, „war von amerikanischen Stellen gewarnt worden, daß sich in Ansbach ... feindliche Elemente aufhielten. Es wurde angeordnet, daß sie nicht in ihren Quartieren, sondern mit geladener Pistole in ihren Büros schlafen und Wachposten aufstellen sollten." Horvay war weitgehend frei von antideutschen Ressentiments und suchte Kontakt zu Deutschen. Er nahm schon bald an den wöchentlichen Treffen einer Gruppe von Ansbacher Intellektuellen teil, zu der Karl Bosl, der spätere

98 Annual Hist. Rep., Det. Ansbach, 1. September 1946, in: NA, RG 260, 10/80-3/6.

99 Schriftliche Mitteilung von Frank D. Horvay vom 27. Januar 1984.

${ }^{100}$ Annual Hist. Rep., Det. Ansbach, 1. September 1946, in: NA, RG 260, 10/80-3/6.

${ }^{10}{ }^{2} \mathrm{Zu}$ Horvay vgl. Who's Who in America, 1972-1973, Vol. I, und die schriftlichen und mündlichen Mitteilungen, die er im Januar 1984 an meine Kollegin Helga Welsh richtete. 
Lehrstuhlinhaber für Bayerische Geschichte an der Universität München, Hans Schregle, der spätere Regierungspräsident von Ober- und Mittelfranken, und Heinrich Pospiech, ein Maler und Bildhauer, gehörten ${ }^{102}$. Man trank Wein und Kaffee und sprach über Literatur, Malerei und klassische Musik. Die meisten amerikanischen Offiziere, nach dem Urteil von Horvay waren „a good number of them ..., wash-outs from combat units“, hatten dafür wenig Sinn. „Hätten wir Bier getrunken und über Baseball gesprochen, so wäre es bestimmt anders gewesen“, meinte Horvay, der seinen Ansbacher Gesprächspartnern Bosl und Pospiech über Jahre hinweg freundschaftlich verbunden blieb. „Nie werde ich den Heiligen Abend des Jahres 1945 vergessen“, erzählte er: „Ich war damals ,charge of quarters', das ist so eine Art Bereitschaftsdienst im Büro der Militärregierung. Das hieß: Ich mußte sogar dort schlafen, das Telefon bedienen und im Ernstfall irgend etwas unternehmen. Ich tat mir selbst sehr leid, denn das ist eine ziemlich unschöne Art Weihnachten zu verbringen, das in Ungarn ... so ähnlich gefeiert wurde wie in Deutschland. Es war fast Mitternacht, als es läutete und zwei Besucher eintraten: Pospiech und Bosl, die Bücher und Lebkuchen als Geschenke brachten." Horvay, der wegen seiner Sprachkenntnisse und guten Kontakte innerhalb der Militärregierung bald als unentbehrlich galt, sprach bei der Einsetzung von Bürgermeistern ein gewichtiges Wort mit. Vor allem aber leitete er im Auftrag der Militärregierung die Ermittlungen im Fall Limpert ein. Seiner Initiative war es in erster Linie zu verdanken, daß Kampfkommandant Meyer in einem amerikanischen Gefangenenlager entdeckt und einem deutschen Gericht übergeben werden konnte ${ }^{103}$.

Cofer und seine Kollegen fielen anfangs in der einem Heerlager gleichenden Stadt Fürth kaum auf. Um so mehr machte eine andere Abteilung der Besatzungsmacht von sich reden: das Counter Intelligence Corps (CIC), das schon bald in üblem Ruf stand. Die Hauptaufgabe des Abschirmdienstes der US-Armee war es, die Streitkräfte vor Spionage, Sabotage und Subversion zu schützen, den deutschen Geheimdienst sowie alle geheimdienstlichen und paramilitärischen Organisationen zu bekämpfen und bestimmte Personengruppen festzunehmen, ferner bei der Auflösung der NSDAP mitzuwirken, die Offiziere des deutschen Generalstabes festzusetzen, Deserteure der Wehrmacht aufzuspüren sowie bei Verstößen gegen die Bestimmungen des Kriegsrechtes zu ermitteln. Zur Personengruppe, die laut SHAEF-,Arrest Categories Handbook“ von CIC sofort zu verhaften war - man betrachtete sie als „Bedrohung für die Sicherheit der alliierten Streitkräfte“ -, gehörten Zehntausende von SS-Leuten, Angehörige des SD und NSDAP-Funktionäre bis hinunter zu den Amts- und Propagandaleitern der Ortsgruppen sowie alle leitenden Beamten der Verwaltung einschließlich Regierungspräsidenten, Landräte und Oberbürgermeister; außerdem alle Personen, die sich durch ihr Verhalten irgendwie verdächtig gemacht hatten. Dies war keine leichte Aufgabe, wie die CIC-Detachments bald erkannten, die sich bei ihren Maßnahmen nur selten auf amtliche Unterlagen oder Akten der NSDAP stützen konnten, sondern sich meist auf Ratschläge und Tips von vertrauenswürdigen Deutschen verlassen mußten $^{104}$.

102 Ebenda.

${ }^{103}$ Vgl. Fröhlich, Herausforderung, S. $248 \mathrm{ff}$.

${ }^{104} \mathrm{Vgl}$. dazu ausführlicher Henke, Die amerikanische Besetzung Deutschlands. 
Das Fürther CIC stand anfangs unter der Leitung von Thomas K. Hodges, einem sehr jungen, unerfahrenen Lieutenant ${ }^{105}$, der - so meinte jedenfalls Cofer - seinen Aufgaben kaum gewachsen war. Der deutschen Sprache unkundig, schlecht ausgebildet und ohne größere Kenntnisse über das Wesen des Nationalsozialismus, war er bald von einem rasch fluktuierenden Schwarm von DP's und Konjunkturrittern umgeben, die ihn bei seiner Arbeit berieten. Sein Kollege Major James K. Dorsett jr. dürfte ihm aus der Seele gesprochen haben, als er im November 1944 meinte: „Angesichts der sehr dürftigen Kenntnisse über Deutschland und der sprachlichen Hürden gibt es eine berechtigte Tendenz, sich ungeeignet zu fühlen für die wirklich wichtige Abwehrarbeit, die getan werden muß. Aber was auch geschieht, wir sind die AbwehrEinrichtung, an der die Aufgabe hängt." ${ }^{106}$ Die Unsicherheit in CIC-Kreisen hatte seitdem eher noch zugenommen, denn nach den ersten Entnazifizierungspannen in Aachen war in der amerikanischen Presse eine Entnazifizierungshysterie ausgebrochen, die auch auf die CIC-Detachments einwirkte ${ }^{107}$. Diese fühlten sich wie mit Argusaugen beobachtet und wollten tunlichst Vorwürfe der Journalisten vermeiden, nicht scharf genug gegen Nazis vorzugehen. Unterschiedlichsten Einflüssen ausgesetzt, schlug die Einheit von Hodges einen unberechenbaren Zickzack-Kurs ein, für den sie bei der besonneneren Militärregierungseinheit nur Kopfschütteln erntete ${ }^{108}$.

Ganz oben auf der „schwarzen Liste“ des CIC für Mittelfranken standen die beiden prominentesten NS-Funktionäre der Region: Julius Streicher und Karl Holz. Der Frankenführer, um den es nach seinem Sturz als Gauleiter 1940 still geworden war, sah dem Kriegsende auf seinem Gut Pleickertshof in der Nähe von Cadolzburg (Landkreis Fürth) entgegen. Als er erkannte, daß sich das Blatt nicht mehr wenden ließe, dachte er an Selbstmord. Das Grab für sich und seine jungvermählte Frau hatte er bereits geschaufelt; dann stieß er aber alle Selbstmordpläne wieder um, legte sich einen falschen Namen zu, klebte sich einen Bart auf, tat sich eine Augenklappe um und suchte Zuflucht in den Alpen, wo ihn amerikanische Soldaten aber trotz seiner Aufmachung erkannten und verhafteten. Im Nürnberger Prozeß wurde er anschließend zum Tode verurteilt und hingerichtet ${ }^{109}$. Für seine langjährige rechte Hand, Karl Holz, der sich schließlich selbst zum Gauleiter aufschwingen konnte, waren Gedanken an Selbstmord und Flucht gänzlich ausgeschlossen. Unter ,allen Umständen in Nürnberg zu bleiben und lieber kämpfend fallen als diese Stadt zu verlassen“, lautete die Devise des blindgläubigen Hitler-Anhängers, an die er sich als einer der wenigen tatsächlich bis zur letzten Konsequenz hielt ${ }^{110}$.

Die übrigen NS-Bonzen und die Spitzen der regionalen Verwaltung der mittelfränkischen Provinz um Ansbach und Fürth gingen den CIC-Detachments früher oder später ins Netz und mußten anschließend meist Jahre im Internierungslager zubrin-

${ }^{105}$ Zum Fürther CIC vgl. NA, RG 260, 9/122-5/13.

${ }^{106}$ Bericht von Headquarters VII Corps, CIC vs Naziism, 24. November 1944, in: NA, RG 332, ECAD, Public Safety.

${ }^{107} \mathrm{Vgl}$. dazu ausführlicher Henke, Die amerikanische Besetzung Deutschlands.

${ }^{108}$ Vgl. S. $109 \mathrm{f}$.

${ }^{109}$ Baird, Testament Julius Streichers, S. 662.

${ }^{110}$ Vgl. Bayern in der NS-Zeit, Bd. I, S.688. 
gen. Karl Häupler, der kommissarische Oberbürgermeister von Fürth, wurde am 19. April 1945 im Rathaus verhaftet und dann in ein Lager in Elsaß-Lothringen verbracht, wo er 1947 Selbstmord verübte. Der Landrat von Fürth, Robert Bracker, war in den Wirren der ersten Besatzungstage zunächst nicht auffindbar gewesen. Die Agenten von CIC schnappten ihn Ende April und brachten ihn in das Internierungslager von Hersbruck. Dort traf er mit seinem Ansbacher Kollegen Rudolf Conrath zusammen, den die CIC-Einheit gleich nach dem Einmarsch abgeholt hatte. Oberbürgermeister und Kreisleiter Richard Hänel aus Ansbach, der sich im April nach Süden abgesetzt hatte, konnte sich noch einiger Wochen Freiheit erfreuen, dann mußte auch er den Weg ins Lager antreten ${ }^{111}$.

Die Verhaftung der oft verhaßten NS-Bonzen und "Goldfasane“ fand den Beifall der Mehrheit der einheimischen Bevölkerung. Anders stand es mit der Verhaftung vieler kleiner Parteigenossen, die der Bevölkerung als harmlos bekannt waren. Solche Aktionen des CIC schmälerten das Ansehen der Amerikaner beträchtlich. In Großhabersdorf und Veitsbronn verstand es kaum jemand, als im Frühjahr 1945 der Propagandaleiter und der Organisationsleiter der NSDAP sowie der stellvertretende Ortsgruppenleiter, der Kassenleiter, und der stellvertretende Amtsleiter der NSV interniert wurden. Noch weniger Verständnis fand es, als in Langenzenn die Verhaftung eines Wehrmachtsangehörigen bekannt wurde; er war von CIC abgeholt worden, weil er vor seiner Einberufung HJ-Führer gewesen war ${ }^{112}$. Heftige Kritik löste es auch aus, als in Roßtal CIC-Angehörige ziemlich wahllos mehrere Parteigenossen und einige Nichtparteigenossen aus ihren Häusern trieben und zum Rathaus dirigierten. „Dort mußten sie die Nacht über im Freien stehen und wurden am anderen Tag früh in das Lager nach Bad Kreuznach gebracht." ${ }^{113}$

Bald tauchte sogar das Schlagwort von der „amerikanischen Gestapo“114 auf. In der Ortschaft Lehrberg im Landkreis Ansbach konnte man sich bis zum Ende der Besatzungszeit nicht damit abfinden, daß der militärische Abschirmdienst den recht beliebten Ortsgruppenleiter verhaftet hatte, einen angesehenen Land- und Gastwirt, für den, wie der neue Bürgermeister am 12. Mai in einem ausführlichen Schreiben versicherte, „bei seiner politischen Betätigung als Ortsgruppenleiter das Wohl der Gemeinde stets oberstes Gesetz“ gewesen sei. „Ohne Rücksicht auf Parteizugehörigkeit und Stand tat er nur Gutes, obwohl er dadurch des öfteren mit den ihm von höherer Parteistelle gegebenen Anordnungen in Konflikt kam. “115 Noch größer war die Empörung, wenn die verunsicherten CIC-Einheiten Personen „mitnahmen“, die in der NS-Zeit verfolgt worden waren, aber aufgrund irgendwelcher Denunziationen in den Verhaftungslisten erschienen. Auf einen solchen Fall bezog sich der Beschwerdebrief einer Frau aus Windsbach an den Chef der Ansbacher Militärregierung, der den Fehler von CIC schließlich ausbügeln konnte:

${ }^{111}$ Vgl. dazu eine Aufstellung der Fürther Militärregierung vom 1. April 1949 über das Schicksal von Fürther NS-Führem, in: NA, RG 260, 9/95-1/87 sowie Amtsgericht Ansbach, Registratur S: Nr. 1,3 und Amtsgericht München, Registratur S: Nr. 5.

112 Vgl. Gendarmerie-Posten Großhabersdorf an Gendarmerie-Kreis Fürth, 26. Mai 1945; Gendarmerie-Posten Langenzenn an LR Fürth, 7. Juni 1945; Gendarmerie-Posten Veitsbronn an Gendarmerie-Kreis Fürth, 26. Mai 1945, in: LRA Fürth, EAP 150.

113 Schriftliche Mitteilung von Michael Wiesinger vom 1. September 1981.

${ }^{114}$ Vgl. dazu ausführlicher Henke, Die amerikanische Besetzung Deutschlands.

115 Bürgermeister von Lehrberg an MilReg, 12. Mai 1945, in: LRA Ansbach, EAP 15-150. 
„Sehr geehrter Herr Commandeur!

Mein Mann wurde am 3. ds. Mts. verhaftet und war ich dieserhalb schon dreimal in Ansbach bei der Kommandantur, aber immer mit negativem Erfolg, da ich trotz stundenlangem Warten nie den richtigen Herrn erreichen konnte. Ich weiß mir nun keinen anderen Weg mehr, als mich schriftlich an Sie zu wenden. - Vorweg bemerken möchte ich, daß mein Mann weder Parteigenosse, noch SA- oder SS-Mann war. Mein Mann war vollständig parteilos. - Mein Mann befand sich in der Zeit vom 15.-26. 8. 1933 in Schutzhaft und wurde in der gröbsten Weise mißhandelt. Sein Rükken, das Gesäß und die Oberschenkel waren vollständig mit Blut unterlaufen und aufgesprungen, er konnte weder sitzen noch liegen. Dadurch hatte mein Mann die Segnungen des Dritten Reiches zur Genüge kennen gelernt und konnte niemals mehr den richtigen Anschluß finden, sondern hielt sich, trotz ungezählter Aufforderungen, von allem was Partei etc. hieß zurück“116.

Das Sternenbanner auf dem Fürther Rathaus, amerikanische Offiziere in der Promenade Nr. 4 und im Ansbacher Schloß - die neuen Herren etablierten sich und waren doch ein Fremdkörper in ihrem Territorium. Bei vielen Besatzungsoffizieren und Mannschaftsgraden waren antideutsche Vorurteile nicht zu übersehen. Manches davon ging offenbar auf die vorangegangenen Ausbildungsprogramme zurück. In den „Special Orders for American-German Relations", die jeder GI im Tornister hatte, erschienen die Deutschen als unsympathisch-verschlagen, denen keinen Moment lang zu trauen sei. Der amerikanische Soldat solle niemals vergessen, „daß das deutsche Volk die Grundsätze des Nationalsozialismus unterstützt“. Weiter hieß es: „Amerikanischen Soldaten ist es verboten, mit Deutschen zu verkehren. Vor allem ist es nicht zulässig, Deutschen die Hände zu geben, ihre Häuser zu besuchen, Geschenke mit ihnen auszutauschen, Spiele und Sport mit ihnen zu treiben, an ihren Tanzveranstaltungen oder gesellschaftlichen Ereignissen teilzunehmen oder sie auf den Straßen oder anderswo zu begleiten." ${ }^{\text {"17 }}$ Im April 1945 gingen zudem die schockierenden Fotos und Filme über die nationalsozialistischen Konzentrationslager um die Welt. Kaum ein Amerikaner blieb davon unberührt; am wenigsten die Juden unter den Besatzern, von denen verständlicherweise viele dazu neigten, alle Deutschen als unverbesserliche Nationalsozialisten anzusehen.

Es dauerte aber nicht allzu lange, bis trotz der „hardliner“ von CIC das Klima zwischen Besatzern und Besetzten entspannter wurde. Ein Sonderkapitel bildeten die vielfältigen Kontakte zwischen deutschen Frauen und amerikanischen Soldaten und Offizieren, die sich in Ansbach vor allem im Gasthaus „Zum Schwarzen Bären“ in der Uzstraße anbahnten, wo die Amerikaner den großen Saal für sich reserviert hatten. Jeden Samstag spielte dort eine Kapelle zum Tanz auf, es gab reichlich zu essen und sogar Vollbier von der Hürnerbrauerei ${ }^{118}$. „Ganz gleich, ob sie verheiratet waren oder nicht", so erinnerte sich Horvay, zahlreiche amerikanische Soldaten hatten schon bald, ungeachtet scharfer Fraternisierungsverbote, deutsche „girl-friends“. „Abhängig von Ausbildung und Erziehung sowie den Interessen der Amerikaner kamen die Frauen

\footnotetext{
${ }^{116}$ Schreiben in: Ebenda, EAP 060.

117 Special Orders for American-German Relations, in: NA, RG 59, 740.00119 Control (Germany)/4-945. '

${ }^{118}$ Mündliche Mitteilung von Robert Joos vom 22. November 1983.
} 
aus den niedrigsten und höchsten gesellschaftlichen Schichten ... Es war damals das erste Jahr nach dem Krieg, und die hergebrachten Normen hatten ihre Gültigkeit verloren. Viele Frauen waren genauso einsam wie unsere Männer ... Es gab natürlich auch andere Gründe, vor allem wirtschaftliche." ${ }^{119}$

Die meisten dieser Verbindungen gingen bald wieder in die Brüche, nur wenige hatten Bestand oder endeten gar vor dem Traualtar. Viele Deutsche mißbilligten diese Art der deutsch-amerikanischen Kontakte. In zahlreichen Städten entstanden 1946/47 gehässige Pamphlete, in denen der Zorn auf die „Ami-Schicksen“ zum Ausdruck kam. Es wimmelte nur so von markigen Sätzen aus dem Repertoire der Nationalsozialisten. Beispielsweise hieß es:

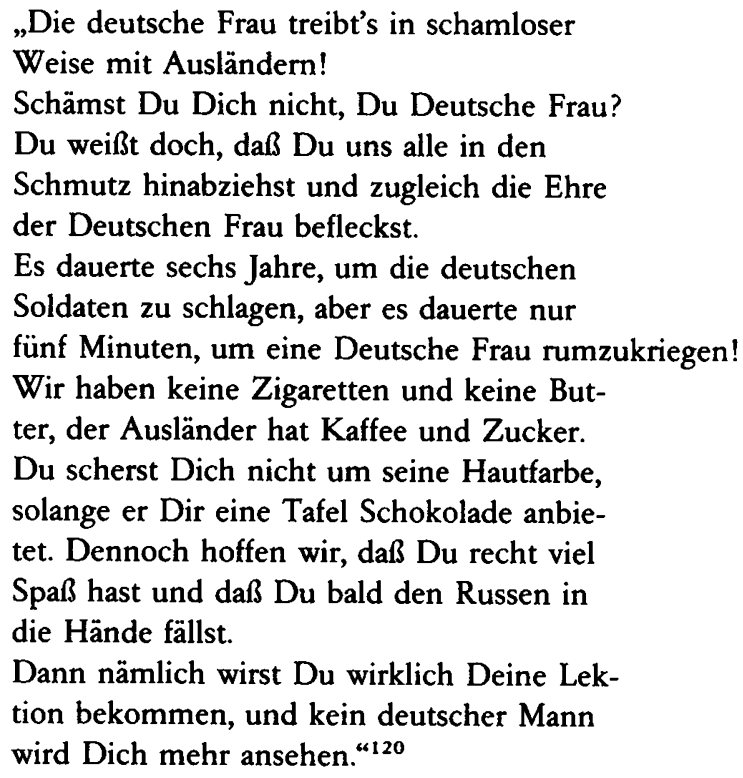

Oft wartete man nicht auf die Russen, die den Ami-Liebchen und Tommi-Bräuten die Lektion erteilen sollten. Einige Mädchen, die mit Besatzungssoldaten gesehen worden waren, wurden verprügelt, anderen die Haare abgeschnitten. In Ansbach mußte sich die Tochter des im Internierungslager einsitzenden ehemaligen Kreisleiters und Oberbürgermeisters viele schiefe Blicke und böse Bemerkungen gefallen lassen, als sie sich mit einem amerikanischen Offizier vermählte. Noch größere Wellen schlug die tatsächlich etwas pikante Eheschließung zwischen einem amerikanischen Richter am District Court und der Frau eines „Alten Kämpfers“ und SA-Obersturmbannführers, der 1938 an den Ausschreitungen der Reichskristallnacht beteiligt gewesen und deshalb 1945 inhaftiert worden war. Als die Frau den amerikanischen Juden

\footnotetext{
${ }^{119}$ Schriftliche Mitteilung von Frank D. Horvay vom 27. Januar 1984.

${ }^{120}$ Christoph Boyer/Hans Woller, „Hat die deutsche Frau versagt?" Die ,neue Freiheit' der Frauen in der Trümmerzeit 1945-1949, in: Journal für Geschichte, 1983, Heft 2, S.36. Vgl. auch RegPräs an bay. Staatsregierung, 22. Juli 1946, in: BayHStA, Reg von Mittelfranken, Berichterstattung 1946, AZ 1-64, Bd. 6. Sowie einige Pamphlete in: NA, RG 260,9/113-2/7.
} 
kennenlernte, saß ihr Mann noch im Lager Hammelburg ein. Sie willigte in die Ehe erst ein, nachdem ihr der Richter versprochen hatte, sich nach Kräften für die baldige Entlassung ihres Mannes einzusetzen ${ }^{121}$.

Die Chefs der beiden Detachments, Cofer und Whitaker, die anfangs manchen als finster und unnahbar erschienen waren, genossen sogar schon bald großes Ansehen in der Bevölkerung. Man schätzte sie wegen ihrer Fairness, und vor allem rechnete man es ihnen hoch an, daß sie die DP's im Zaum zu halten verstanden und manche Fehler des CIC rückgängig gemacht hatten. Ein halbes Jahr nach der Etablierung der Militärregierung standen sie auch mit "ihren" Landräten und Bürgermeistern schon fast in freundschaftlichem Kontakt ${ }^{122}$. Diese Vertrauensbasis konnte auch durch die im Sommer 1945 einsetzenden überzogenen amerikanischen Entnazifizierungsmaßnahmen nicht mehr ernstlich erschüttert werden. Besonders deutlich kam dieses gewandelte Verhältnis in den Mitte 1946 anlaufenden Planungen zur Gründung eines deutsch-amerikanischen Clubs in Ansbach zum Ausdruck, der dann am 17. Januar 1947 im Gebäude des CIC aus der Taufe gehoben wurde. Dieser Gründung, der ersten dieser Art in der amerikanischen Zone, gehörten die führenden Militärregierungsoffiziere und vierzehn im öffentlichen Leben stehende Deutsche an, so etwa Landrat Richard Neff, Oberbürgermeister Ernst Körner, Regierungspräsident Hans Schregle und der CSU-Landtagsabgeordnete Georg Mack. Wilhelm Zimmerer, die graue Eminenz der SPD, führte den Vorsitz, Whitaker war sein Stellvertreter. Das proklamierte Hauptziel des Clubs war die „Förderung der Verständigung zwischen Deutschen und Amerikanern“. In der Praxis entwickelte sich der „Ansbacher Club“ aber schnell zu einer Art deutsch-amerikanischem Stadtrat, in dem sich anstehende Probleme in angenehmer Umgebung regeln ließen ${ }^{123}$.

Es roch zwar für viele engstirnige und national denkende Ansbacher und Fürther nach Verrat, wenn die Ortshonoratioren mit der Militärregierung zusammenhockten oder überhaupt mit den Amerikanern verkehrten, gleichwohl ergaben sich in den ersten Besatzungsjahren bei vielen Gelegenheiten Kontakte mit den „Besatzern“ und ihren Familienangehörigen, die inzwischen den Vätern und Männern nach Europa nachgefolgt waren. Zum Thanksgivingday 1946 luden 54 amerikanische Kinder über 100 Fürther Altersgenossen ein, um unter der Regie von Peter Frankenfeld, der damals seine ersten Schritte als Unterhaltungskünstler machte, eine „echte amerikanische Party“ zu feiern. „Demokratie im Kinderstaat“, überschrieben die Nürnberger Nachrichten diese Initiative der amerikanischen Kinder, die auf deutscher Seite viel Beifall fand ${ }^{124}$. Jagdliebhaber in der Militärregierung wie der Ankläger beim District Court in Ansbach William Canfield gingen mit deutschen Waldbesitzern oder -pächtern zur Jagd und debattierten über die Vorzüge der deutschen und amerikanischen Büchsen. Die Parteizugehörigkeit spielte dabei kaum eine Rolle, wie der spätere Ansbacher Oberbürgermeister Ludwig Schönecker erzählte, der - selbst Pg seit 1933 und Kreisjägermeister im Dritten Reich - mit Canfield häufig auf einen Rehbock ansaß. Nach erfolgreicher Jagd blieben sie dann noch bei Bier und Frankenwein zusammen,

\footnotetext{
${ }^{121}$ Mündliche Mitteilungen von Ludwig Schönecker und Wilhelm Eichhorn vom 17. August 1983.

122 Vgl. dazu das Kapitel über den Verwaltungsaufbau (S. $108 \mathrm{f}$ ).

${ }^{123}$ Zum Ansbacher Club vgl. die Unterlagen in: NA, RG 260, 10/49-1/23 und Fränkische Landeszeitung vom 15. März 1947.

${ }^{124}$ Nümberger Nachrichten, Fürther Ausgabe, vom 27. November 1946.
} 
tauschten zu fortgeschrittener Stunde Männerwitze aus und - so Schönecker - bestätigten sich in den antisemitischen Ressentiments ${ }^{125}$.

Die Militärregierung, obwohl - wie noch gezeigt wird - von vielen vor allem wegen des harten Säuberungskurses angefeindet, gehörte bald zum städtischen Leben. Erst in den fünfziger Jahren, als die Amerikaner verbündete Streitkräfte in der Bundesrepublik stationierten, begann der Rückzug in die Anonymität der Kasernen. In den ersten Nachkriegsjahren war das anders; dem gestrengen Professor Dorn ging das „Fraternisieren“ viel zu weit. Er diagnostizierte 1949 sogar, die Militärregierung in Bayern werde von der „bayerischen Atmosphäre aufgesogen“126. 